
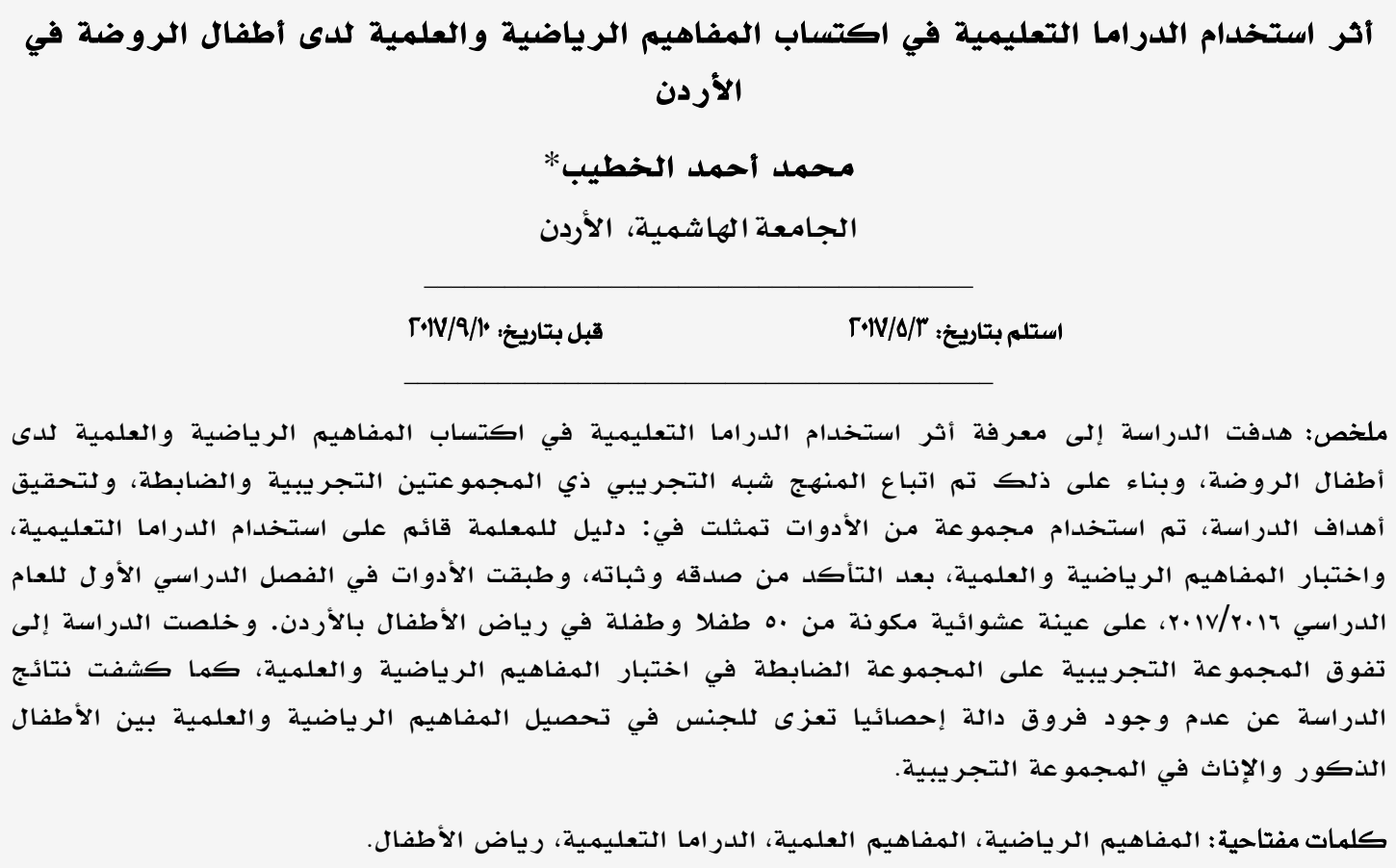

\title{
The Effect of Using Educational Drama on Kindergarten Children's Acquisition of Mathematical and Scientific Concepts in Jordan
}

Mohammad A. Al-Khateeb*

The Hashemite University, Jordan

\begin{abstract}
The study aimed to examin the effect of using educational drama on kindergarten children's acquisition of mathematical and scientific concepts. A quasi-experimental method with experimental and control groups was used to achieve the objectives of the study. Various instruments were used, including a teacher's guide based on educational drama strategy and a scientific/mathematical concepts test. After validating these instruments, they were applied on a random sample of 50 kindergarten children during the first semester of school year 2016/2017. The study concluded that the experimental group outperformed control group on the scientific/mathematical concepts test. The findings also revealed that there were no significant statistical differences attributed to gender of the experimental group in the acquisition of such concepts.
\end{abstract}

Keywords: Mathematical concepts, scientific concepts, educational drama, kindergartens.

*Mkm7879@hu.edu.jo 
لرياض الأطفال يعتبر كخيوط أساسية في النسيج العام للمنهج، حيث يتعلهم الأطفال

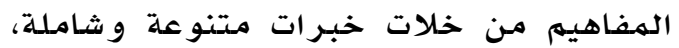
تثري المنهج، و تجذب الطفل، وتثير اهتمهامـه،

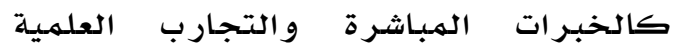

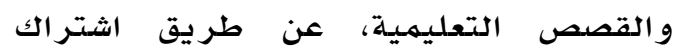

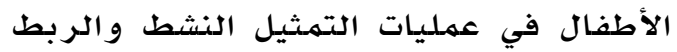

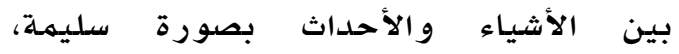

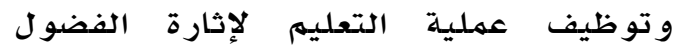
الطبيعي لدى الطفل للتعرف على البيئة التي

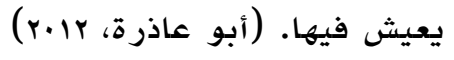

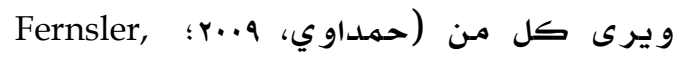

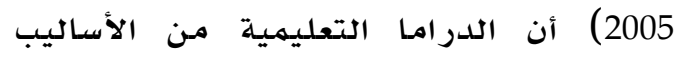

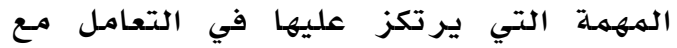

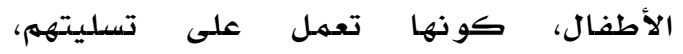
و مساعدتهم في اكتشاف قدراتهم الإبداعية

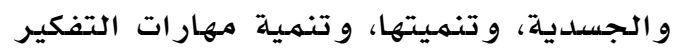
لديهم، وركلها أهداف نسعى إلى تحقيقها ولى تهيها على الصعيدين التربوي والتعليهي. ويرى إنى

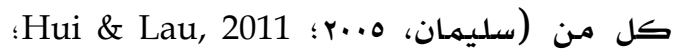
(Mages, 2013 تتحدد قيمتها في أذها تعتبر ان وسيطا مهما

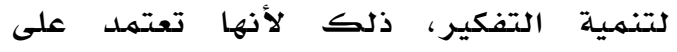
الاكتشاف، كما يعتبر التهثيل الدرامي

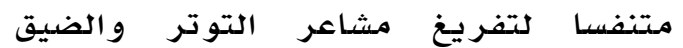
و الغضب التي يعاني منها الطفل بطريقة صحيحة، ويساعد الطفل على فهم وجهات نظر الآخرين من خلاله، وأدائه لدورهمر. وتتبلور أهمية الدر اما كإحدى استر اتيجيات التعليهم والتعلهم، بأنها طريقة لإيصال الأفكار التي ترتبط بالحياة الحقيقية للطلبة، ومزودة لبيئة تفاعل صفي هادف، وذلكي بلكياه

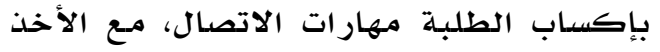
بعين الاعتبار أن اللغة ليست سوى جزء مناء من مناب هذا النشاط، والجزء الآخر هو مركب من

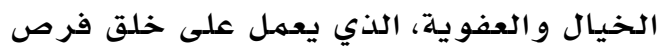

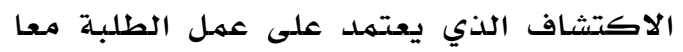

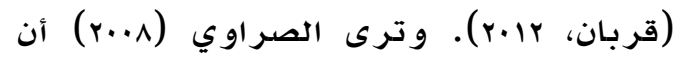

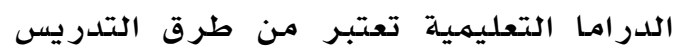

تعد مـرحلة ريـاض الأطفال من المـر احل

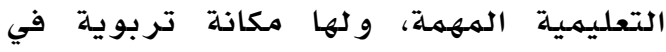

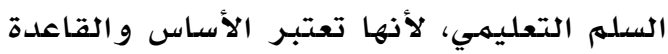

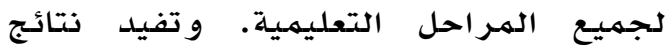
البحوث أن مرحلة رياض الأطفال - ما قبل الصف الأول - هي مرحلة نمو عقلي سريع

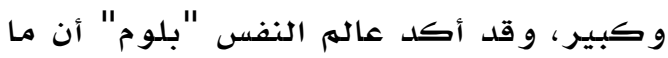
يقارب من •م\% من النمو العقلي يتم خلاسل

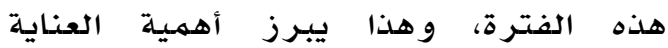
بالأطفال في هذه الهـرحلة، والتي تعتبر مرحلة تكوين مفاهيه و أساليب تفكير و تعلهم

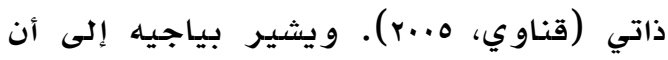
البناء العقلي للطفل يتكون شيئا فشيئا مـع نهاية الهرحلة الحس حركية، و بـاية ظهور

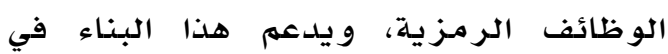

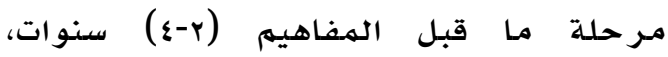
ويصبح أكثر نضدا في مرحلة العمليات

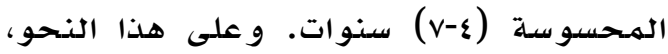
يلاحظ الطفل الأشياء المـختلفة، ويميز ما لهاء بينها من تشابهات واختالافات، حيث يستطيع

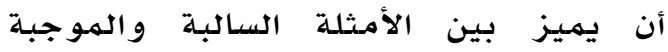
للهفهوم، و يقوم بعهلية التصنيف. (بلدوي، (Bedore, 2004 ? r.1)

و يؤكد بطرس (r.vv) على أهمية تعله

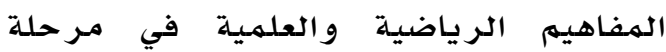

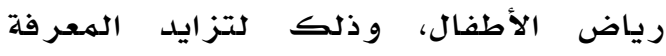

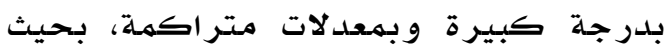
لهم يعد في مقدور أي إنسان، مههما كانت

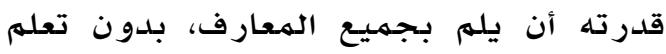
المفاهيم، وكذلك فإن إن تعلم المفاهيم الرياضية و العلهية يساعد على تفسير الكثير

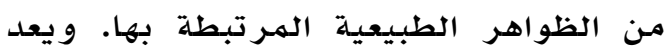
تعلم المفاهيم في الصغر ضرورة لكلأطفال لتجنب فهم الظواهر الطبيعية فهما خاطئًا، وقد دلت البحوث العلميية على أن تعلهم مفاهيم جديدة أسهل بكثير من تصحيح مفاهيم خاطئة. لذلك، فإن توفر الهفاهيهم الرياضية

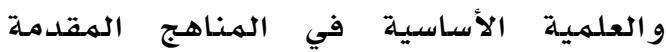


العملية، و مقابلة معلمات رياض الأطفال،

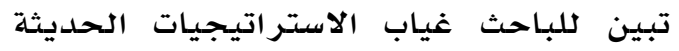

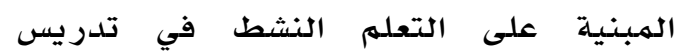

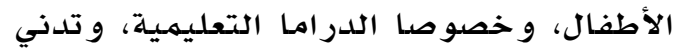

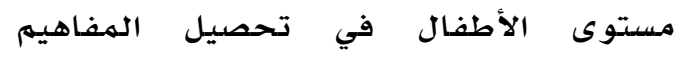
الرياضية و العلمية، و عدم تهكن استر اتيجيات التدريس التي تستخدم في تدريس الأطفال

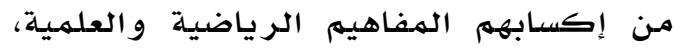

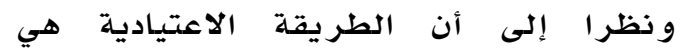

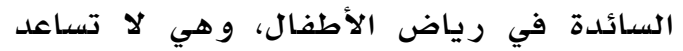

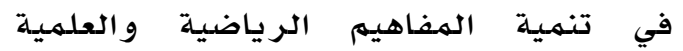

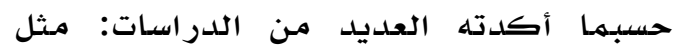

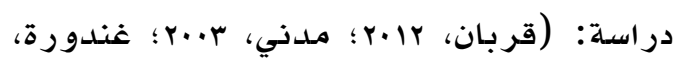

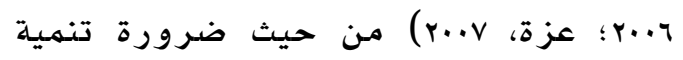

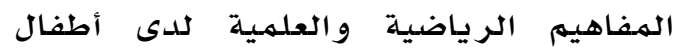

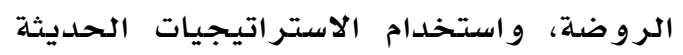

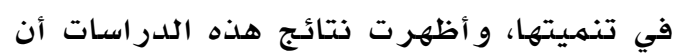

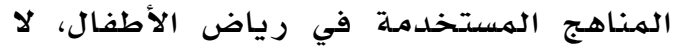

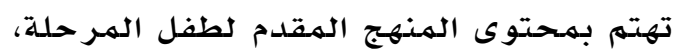
وأن تعليم الهفاهيم يكون دون مستوى الهى الطفل العقلي، و أنه عند تدريسها للطفل قديم لدول لا تكون مثيرة له، وقد لا لا يعيرها ها اهتمامـه.

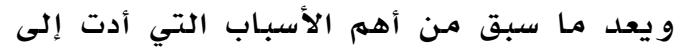

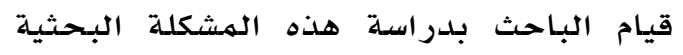

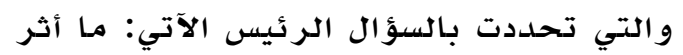

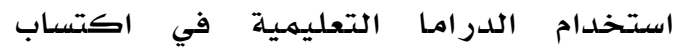

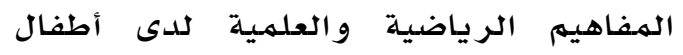
الروضة في محافظة الزرقاء؟ ويندرج تحت الته هذا السؤال الأسئلة الفرعية الآتية: 1. ما أثر استخدام الدراما التعليمية و التفاعل بين طريقة التدريس و جنس التس

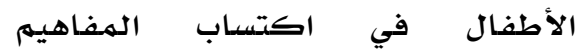

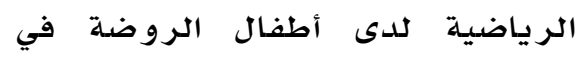
محافظة الزر قاء؟ r. ما أثر استخدام الدراما التعليمية

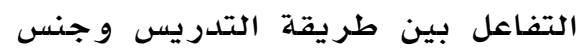
الأطفال في اكتساب الهفاهيم العلهية

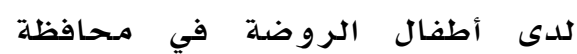

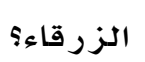

الههمة لأطفال الروضـة، وذلك لأنها تعمل

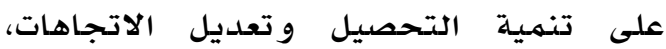
وتنهي خيال الأطفال و تؤدي إلى الإبداع، وتطور الوعي الذاتي لديهم، وتحقق التكامل ما بين النشاط العقلي و البدني، ووتثير انتبـاه الأطفال تجاه ما يشاهدونه و يسمعونه. و في هذا الصدد أجرى أبو ستة (؟...r) دراسـة

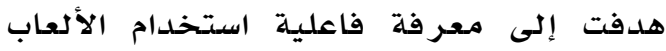

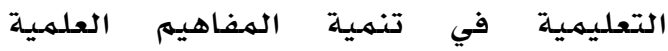
والرياضية لأطفال الروضة، وقسمت عينة

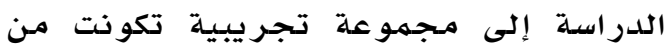

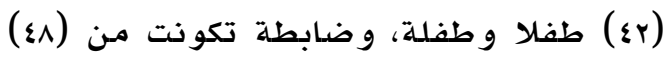
طفلا وطفلة من أطفال الروضلة، في مدينة

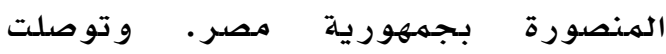

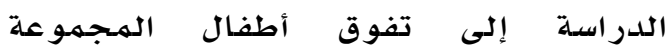

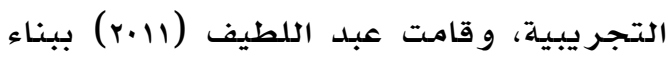
بر نامـج أنشطة فنية لاكتساب بعض وفامبت المفاهيم

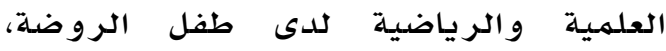

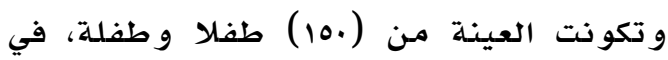

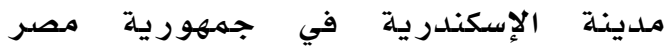
العربية، وتوصلت الدراسة إلى أن الأنشطة الفنية تلعب دورا مههما في اكتسـاب المفاهيم

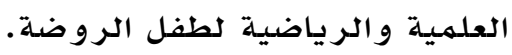

وقد أشار العديد من الههتمين بالدراما

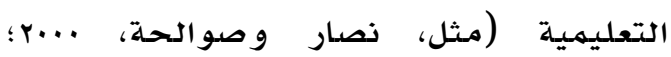

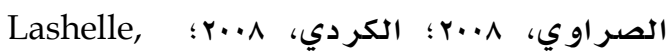

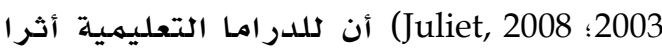
كبيرا على سلوك الأطفال الإيجابي، وتمـرير

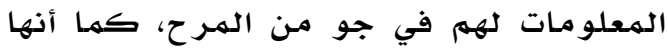
تدرب الأطفال على اكتساب المفاهيه، وهي

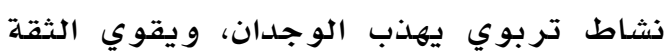

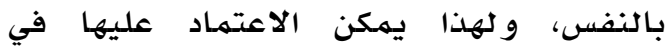

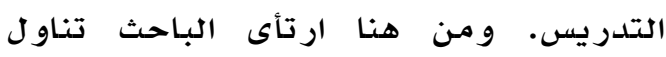

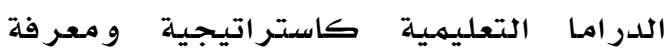
أثرها على اكتساب الأطفال للمفاهيه الر ياضية و العملية.

\section{مشكلة اللدراسة}

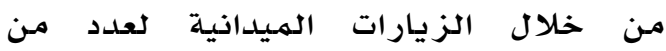
الروضات، والإشراف على طالبات التربية 


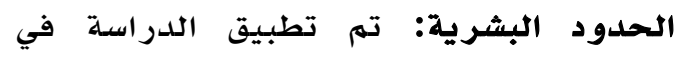

رياض الأطفال في روضة الزهور، وهي وهي

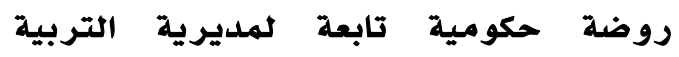
والتعليم لمنطقة محافظة الزرقاء الأولى. الحدود الموضوعية: اقتصرت الدراسـة على تسعة مفاهيم رياضية و علميـة أسـاسية هي الهيه (الأثكال الهندسية، الوزن و الحجمه، المفاهيم ولهيه

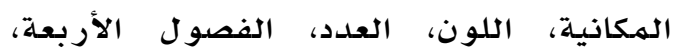

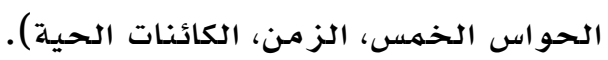
مصطلحات الدراسة الدراما التعليمية: يعرفها اللوح (عا.ب، ص. | (IV النشاطات، التي يقوم بها الأطفال، بتوجيه من

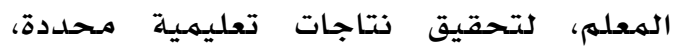

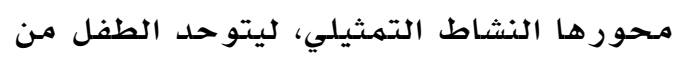

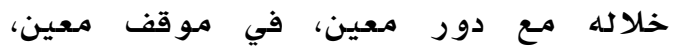

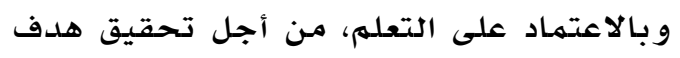

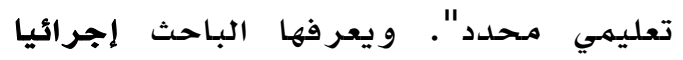
بأنها: الطريقة التي يتم فيها تحويل المادة التعليمية إلى نصوص در دامية، و مشاهد حوارية، وتقوم الهعلمـة بمساعدة الأطفال

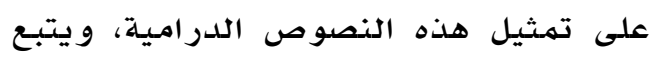
هذا العرض مناقشة، وطرح أسئلة تقويمية

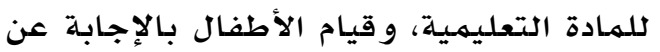

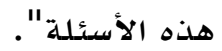

المفاهيم الرياضية: يعرفها بلدوي (rا.r، ص. rr) بأنها "الصورة الذهنية الذية التي تتكون لدى الفرد، نتيجة تعميهم صفات وخصائص، استنتجت من أشياء متشابهة، على أشياء يتهم

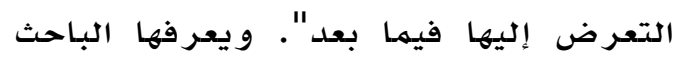

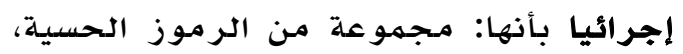

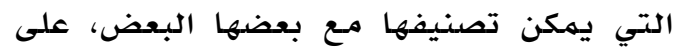

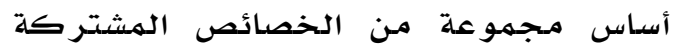

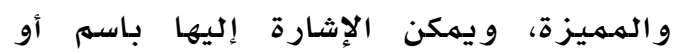
برمز، وتقاس بالدرجة التي يحصل عليها الطفل في اختبار المفاهيم الرياضية الذيا بهي أعده الباحث. احمي

$$
\text { أهداف الدراسة: هدفت الدراسـة إلى: }
$$

1. معرفة أثر استخدام الدرراما التعليمية و التفاعل بين طريقة التدريس وجنس التر التس

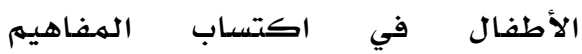

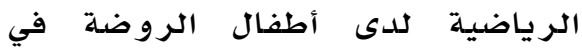
محافظة الزرقاء.

r. معرفة أثر استخدام الدراما التعليمية و التفاعل بين طريقة التدريس وجنس التر التس الأطفال اكتساب المفاهيم العلمية لدى لدئ أطفال رياض الأطفال في محافظة

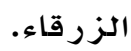

\section{أهمية الدراسة}

تنبع أهمية هذه الدراسـة من كونها تقدم

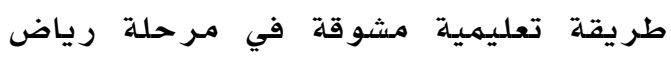
الأطفال، حيث تساعد الأطفال على التعلم بسهو للة، كما يمكن أن تسـاعد معلمات رلات رياض

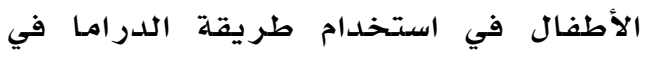
التعليم، كما أنها يمكن أن تزود واضعي النيا

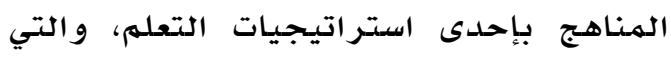
قد تتناسب و فئة أطفال الرياض، والاستر شـاد بها في اختيار وتطوير الاستر اتيجيات

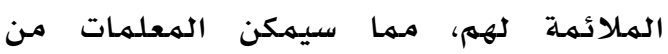
التفاعل الجيد مـع هذه الفئلة، لتحقيق أهداف

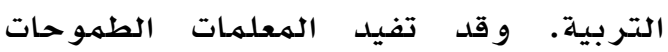
الر اغبات في تطبيق الحديث مـن استر اتيجيات التعلم النشط المتمثلة في الدرامـا التعليمية،

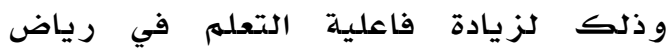
الأطفال، و قد يزيد استخدام الدراما التعليميلة

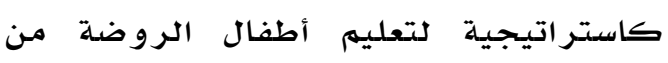
حبهم ورغبتهم في التعلم وزيادة تقبلهم

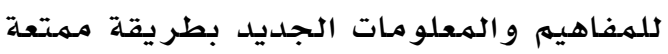
و مشوقة. حلود اللدراسة الحلدود المكانية: تم تطبيق الدراسة في

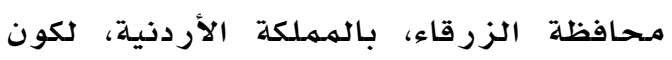
الباحث يقيم فيها.

الحدود الزمانية: تمم تطبيق الدراسـة في

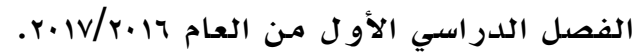




\section{عينة الدراسة}

تمثلت عينة الدراسة بروضدة من ماض رياض الأطفال في منطقة محافظة الزرقاء، وتم

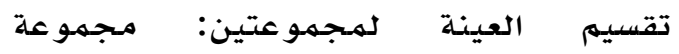
تجريبية؛ درست باستخلدام الدراما التعليميلة، و مجمموعة ضابطة: درست

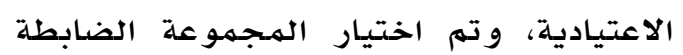

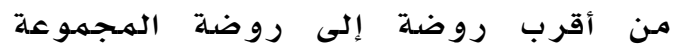

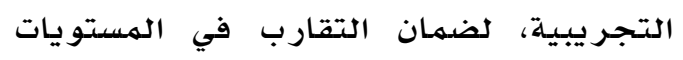

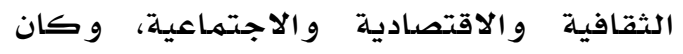

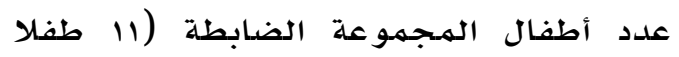

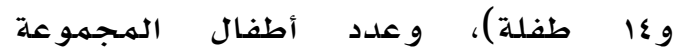

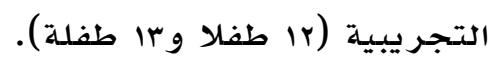
ضبط المتغيرات المؤثرة على التجربة تم ضبط المتغير ات التي يمكن أن تؤثر على كفاءة المتغير المستقل، كما يلي: العمر الزمني: تمت مر اجعة سجلات الأطفال،

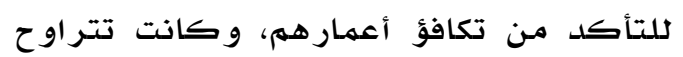
بين (ع-7) سنوات. المستوى الاجتماعي والثقافي والاقتصادي: قام الباحث باختيار أفراد العينة من منطقة واهنة

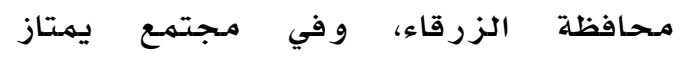
بالتقارب في المستويات الثقافية والاقتصادية

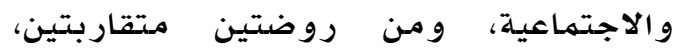

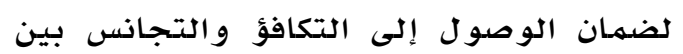

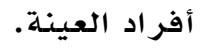

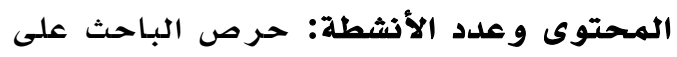

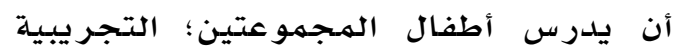

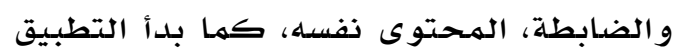
و شرح المفاهيم في الفصل الدراسي الأول

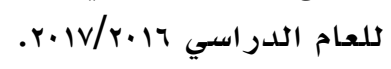

التأكد من تكافؤ المجموعتين في اكتساب المفاهيم العلمية والرياضية: و ذلك بتحديد

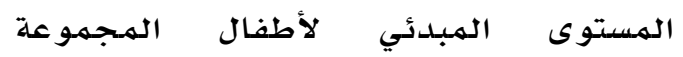

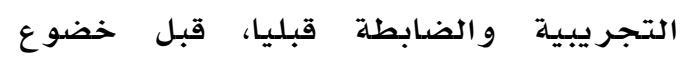

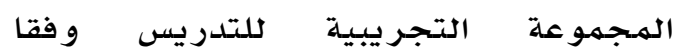
لاستخدام الدر اما التعليميـة.
المفاهيم العلمية :يعرفها أبو عاذرة (r.r.r،

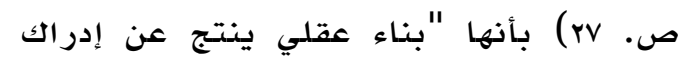
العلاقات الموجودة بين الظواهر أو الحوادث لهاء الهون

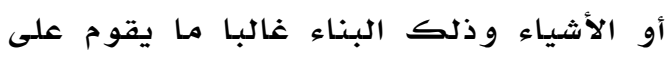
أساس تنظيهم تلك الظواهر أو أو الأثياء في فياء

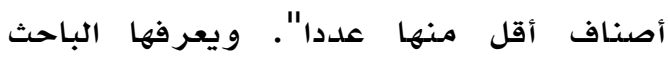
إجرائيا بأنها: هي نوع من المفاهيم التي يجب اهب

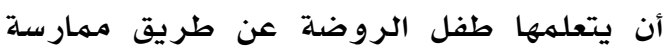
نشاطات مختلفة، وهي المفاهيم التي يستطيع

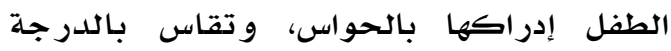
التي يحصل عليها الطفل في اختبار المفاهيم العلمية الذي أعده الباحث.

\section{منهج اللدراسلة}

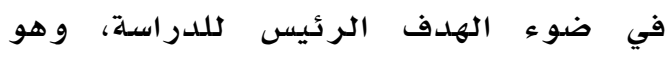

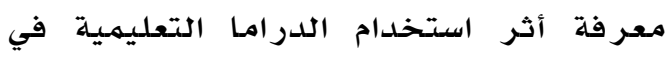

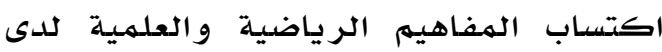

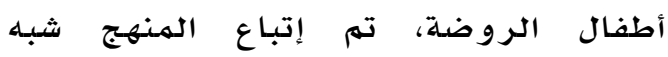

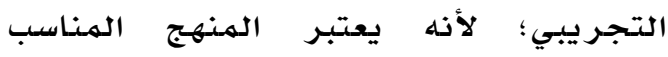

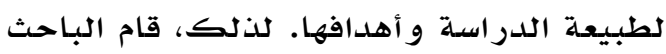
وفق هذا التصميم باختيار مجموعتين لتكون

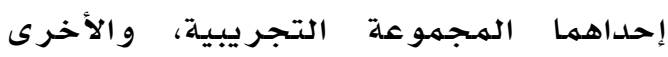
المهجمو عة الضدابطة.

متغيرات الدراسة: تمثلت متغيرات الدراسة المتغير المستقل: طريقة التدريس و لها

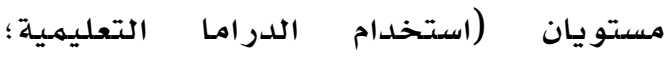
الطريقة الاعتيادية ) المتغير التابع: اكتساب المفاهيه الرياضيـة و العلمية لدى أطفال الرووضدة. مجتمـع الدراسة تكون مجتمع الدراسة من مـميع أطفال رياض الأطفال، بمنطقة محافظة الزرقاء

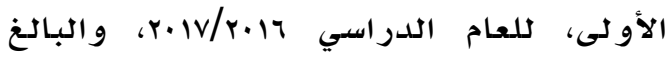

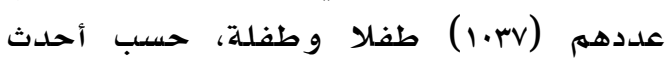
إحصائية رسميلة. 
اختيار تسعة مفاهيم رياضيـة و علميـة

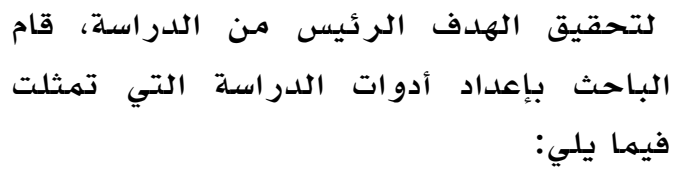

\section{اختبار المفاهيم الرياضية و العلمية}

الهفاهيم العلمية و والهتهثلة ب:(اللون، الفصول الهيث الأربعة، الكائنات

$$
\text { الحية، الحواس الخون، الفمس، الزمن). }
$$

ا. هدف الاختبار قياس اكتساب الأطفال

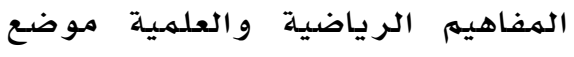

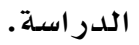

\section{إعداد جدول المواصفات}

قام الباحث بإعداد جدول للمواصفات

r.ام الباحث بالاطلاع على الدراسات

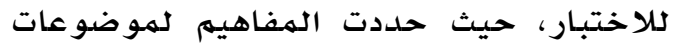

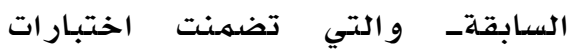

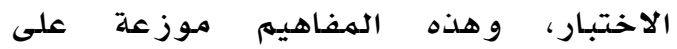

للمفاهيم الرياضية أو العلمية مثل مثل

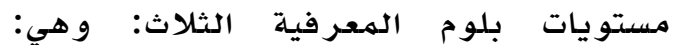

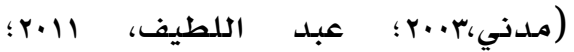

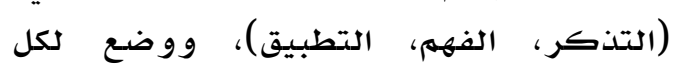

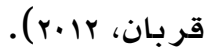

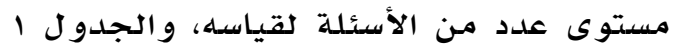

r. بعد اطلاع الباحث على مناهـ رياض يوضتح ذلك.

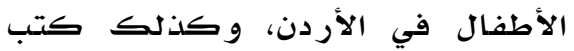

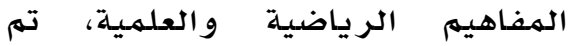

\begin{tabular}{|c|c|c|c|c|c|c|}
\hline الدرجة & الوزن النسبي & عدد الأسئلة & أرقام البطاقات & عدد البطاقات & المفاهيم الرياضية والعلمية & المستوى \\
\hline \multirow{7}{*}{11} & \multirow{7}{*}{$\%$ \% १, ६ } & \multirow{7}{*}{11} & $r, 1$ & $r$ & مفهوم الأشكال الهندسية & \multirow{7}{*}{ ا التذكر } \\
\hline & & & $r, r, l$ & r & المفاهيم المكانية & \\
\hline & & & 1 & 1 & مفهوم الفصول الأربعة & \\
\hline & & & $r, 1$ & r & مفهوم الحواس الخمس & \\
\hline & & & $\varepsilon, r$ & r & مفهوم الزمن م & \\
\hline & & & 1 & 1 & مفهوم اللون & \\
\hline & & & r & 1 & مفهوم العدد & \\
\hline \multirow{6}{*}{ v } & \multirow{6}{*}{$\% r \cdot, r$} & \multirow{6}{*}{ v } & r & 1 & المفاهيم المكانية & \multirow{6}{*}{ الفهم } \\
\hline & & & r & 1 & مفاهيم اللون & \\
\hline & & & 1 & 1 & مفهوم العدد & \\
\hline & & & $\varepsilon$ & r & مفهوم الفصول الأربعة & \\
\hline & & & 1,5 & r & مفهوم الحواس الخمس & \\
\hline & & & r & 1 & مفهوم الزمن & \\
\hline \multirow{8}{*}{17} & \multirow{8}{*}{$\% \circ$} & \multirow{8}{*}{17} & $\varepsilon, r$ & r & مفهوم الأشكال الهندسية & \multirow{8}{*}{ التطبيق } \\
\hline & & & $r, r, l$ & r & مفهوم الوزن والحجم & \\
\hline & & & $\varepsilon, r$ & r & مفاهيم اللون & \\
\hline & & & $\varepsilon, r$ & r & مفاهيم العدد & \\
\hline & & & r & 1 & مفهوم الفصول الأربعة & \\
\hline & & & $r ، \varepsilon$ & r & مفهوم الحواس الخمس & \\
\hline & & & 1 & 1 & مفهوم الزمن & \\
\hline & & & $r, r, l$ & $r$ & مفهوم الكائنات الحية & \\
\hline$r \varepsilon$ & $\% 1 \ldots$ & $r \varepsilon$ & & $r \varepsilon$ & 9 & الإجمالي \\
\hline
\end{tabular}

جدول 1

جدول مواصفات اختبار المفاهيم الرياضية العلمية، والوزن النسبي للمستويات 
صياغة مفردات اختبار الهفاهيم الرياضية طبيعة الاختبار

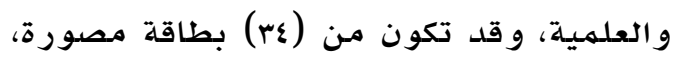

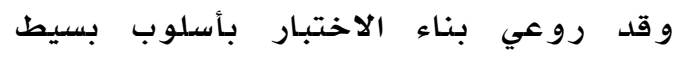

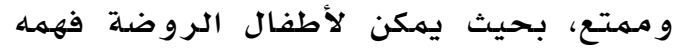

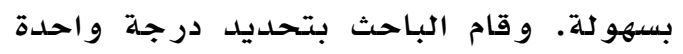

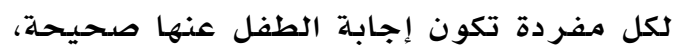
و صفر عن الإجابة الخاطئة، وبذلك تكون

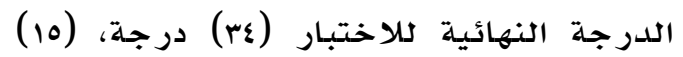

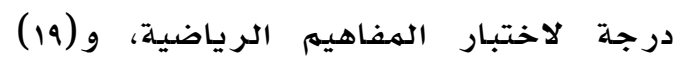
درجة لاختبار المفاهيم العلميلة. الصلدق الظاهري: تم عرض الاختبار على

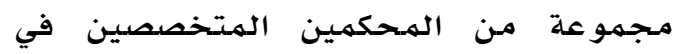

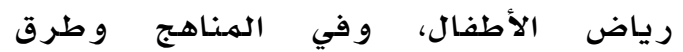

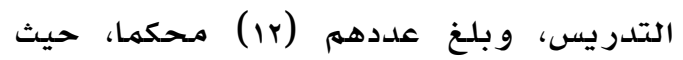
طلب الباحث منهم إبداء رأيهم في:

تنوعت أسئلة الاختبـار بين أسئلة التصنيف،

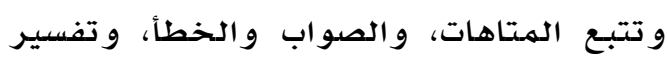

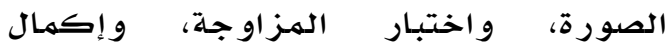

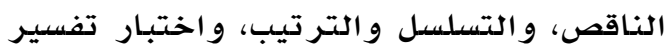

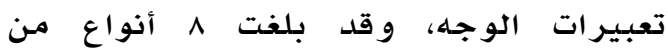

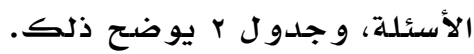

و من خلال اطلاع الباحث على العديد من أنواع الاختبارات التي تقيس المفاهيم

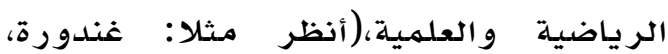

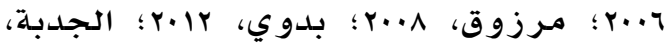

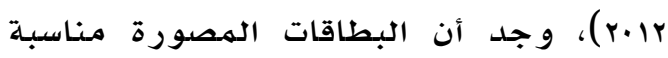
لتصميم الاختبار، حيث أنها لا تتأثر بذاتية

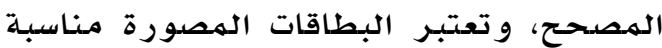

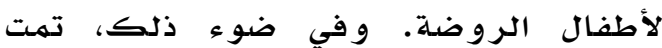

اختبارات المفاهيم الرياضية والعلمية، واللوزن النسبي لنوع الاختبار والدرجة المخصصة

\begin{tabular}{|c|c|c|c|c|c|}
\hline الدرجة & الوزن النسبي & عدد الأسئلة & عدد البطاقات & المفاهيم الرياضية والعلمية & نوع الأسئلة \\
\hline \multirow{6}{*}{$1 \cdot$} & \multirow{6}{*}{$\% \curlyvee ৭, \varepsilon$} & \multirow{6}{*}{1.} & 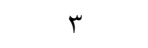 & الأشكال الهندسية & \multirow{6}{*}{ التصنيف } \\
\hline & & & r & الوزن والحجم & \\
\hline & & & 1 & اللون & \\
\hline & & & 1 & 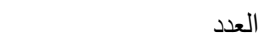 & \\
\hline & & & r & الحواس الخمس & \\
\hline & & & 1 & الكائنات الحية & \\
\hline \multirow{3}{*}{ r } & \multirow{3}{*}{$\% \wedge, \wedge$} & \multirow{3}{*}{ r } & 1 & الأشكال الهندسية & \multirow{3}{*}{ ت ت ت تبع المتاهات } \\
\hline & & & 1 & العدد & \\
\hline & & & 1 & الحواس الخمس & \\
\hline \multirow{2}{*}{ r } & \multirow{2}{*}{$\% 0,9$} & \multirow{2}{*}{ r } & 1 & الوزن والحجم & \multirow{2}{*}{ الصح والخطأ } \\
\hline & & & 1 & 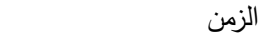 & \\
\hline \multirow{3}{*}{ V } & \multirow{3}{*}{$\% r \cdot, r$} & \multirow{3}{*}{ V } & $\varepsilon$ & مفاهيم مكانية & \multirow{3}{*}{ تفسير الصورة } \\
\hline & & & 1 & 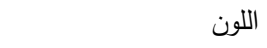 & \\
\hline & & & r & الفصول الأربعة & \\
\hline \multirow{2}{*}{ r } & \multirow{2}{*}{$\% \wedge, \wedge$} & \multirow{2}{*}{ r } & 1 & اللون & \multirow{2}{*}{ 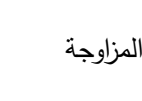 } \\
\hline & & & r & الكائنات الحية & \\
\hline \multirow{4}{*}{0} & \multirow{4}{*}{$\% \backslash \varepsilon, V$} & \multirow{4}{*}{0} & 1 & 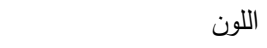 & \multirow{4}{*}{ إكمال الناقص } \\
\hline & & & 1 & 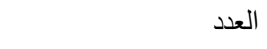 & \\
\hline & & & r & الفصول الأربعة & \\
\hline & & & 1 & 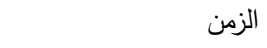 & \\
\hline \multirow{2}{*}{ r } & \multirow{2}{*}{$\% \wedge, \wedge$} & \multirow{2}{*}{$r$} & 1 & العدد & التسلسل \\
\hline & & & r & 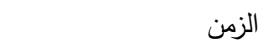 & 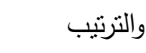 \\
\hline 1 & $\% r, q$ & 1 & 1 & الحواس الخمس & تفسير تعبير \\
\hline$r \varepsilon$ & $\% 1 \ldots$ & $r \leq$ & $r \leq$ & & الإجمالي \\
\hline
\end{tabular}


ب- حساب ثبات الاختبار: تم حساب الثبات

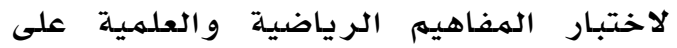

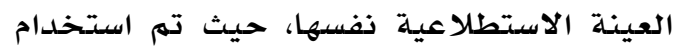

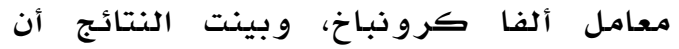

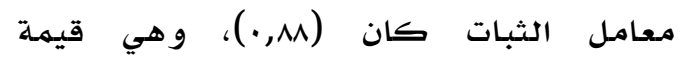
مرتفعة مـما يدل على الاختبار يتصف بدرجة مر تفعة مـن الثبات.

ج- تحديل معاملات الصعوبة والتمييز

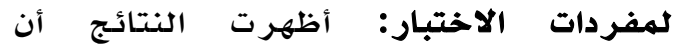

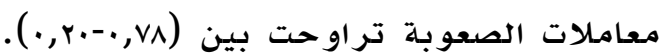

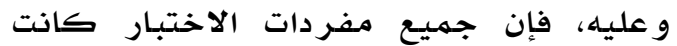

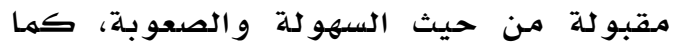
تراوحت معاملات التمييز لمفردات الاختبار

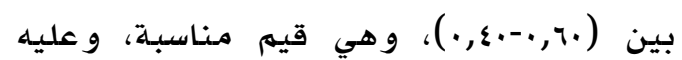
فقد تم قبول جميع مفردات الاختبار من حيث قيم معامل التمييز.

د- تحديل الزمن المناسب لاختبار: تم حساب زمن الاختبار عن طريق حسـاب الزمن الذي استغرقه أول طفلا أنهى إجابة الاختبار

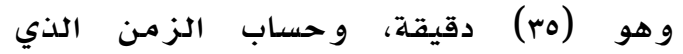
استغرقه آخر طفل أذهى إجابة الاختبار وهو

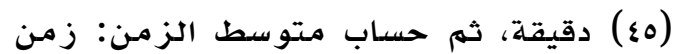
الاختبار = (rot هـ - التحقق من وضوح تعليمات الاختبار ومفرداته: لهم يرد أي استفسار من قبل

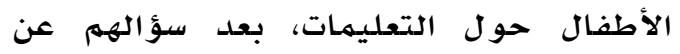
ذلك. وهذا يدل على وضوح التعليمات.

إعداد دليل المعلمة

بعد اطلاع الباحث على عدد من الأدبيات

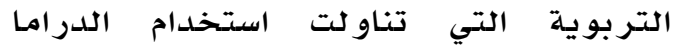

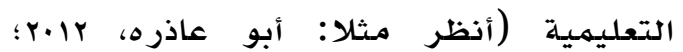

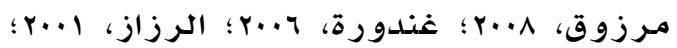
،Clements, 2006 Cokadar \& Yilmaz, 2001

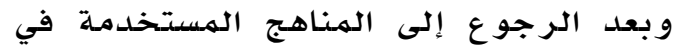
رياض الأطفال؛ تم إعداد دليل لتسترشد به به إهـاه

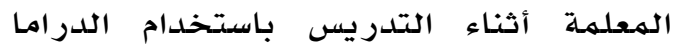

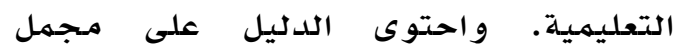
المفاهيم الرياضيلة و العلمية موضع الدية الدراسلة،

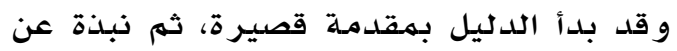

مدى صلاحية الاختبار لقياس الهفاهيه الرياضيلة و العلمية ؛ و مدىى مناسبة كل سؤال

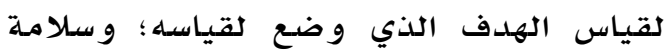

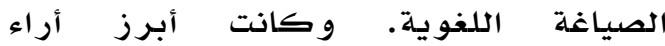

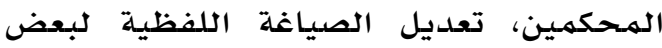

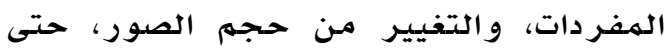
تتناسب مـع خصائص الطفل المعر فية، وبناء على آراء المـحكمين قام الباحث بإجراء التعديلات المطلوبة أهي.

التجربة الاستطلاعية

تم تطبيق الاختبار على عينة استطلاعية

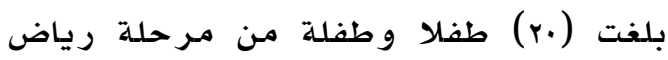

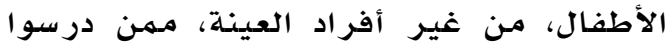
هذه الهفاهيه مسابقا، حيث لقام البـاحث بالاتفاق مـع معلممة بتدريس هذه المفاهماهيم للعينة الاستطلاعية، قبل أن يقوم الباحث بالتطبيق الميداني للدراسلة، و ذلك بهدف: أ- حساب الاتساق الداخلي: تم التحقق من

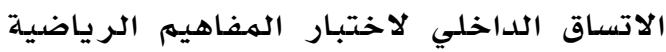
و العلمية، حيث قام الباحث بحسـاب معامل ارتباط بيرسون بين درجـة كل فقرة من فئ

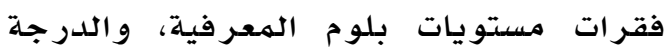
الكلية للمستوى التي تنتهي إليه هذه الفقرة،

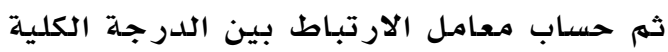
لكل مستوى من مستويات بلوم الهـعرفية،

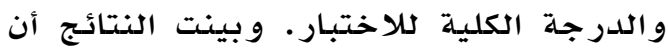

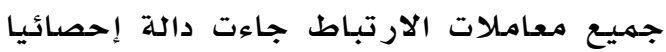

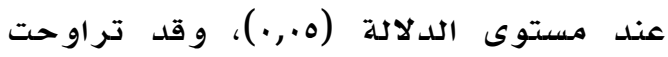

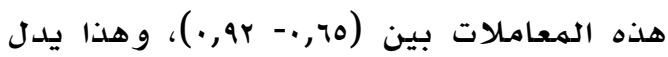
على أن جميع فقرات الاختبـار المفاهيم

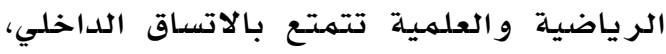

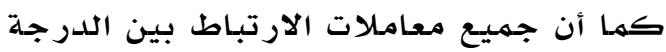
الكلية لكل مستوى والدرجة الكلية للاختبار

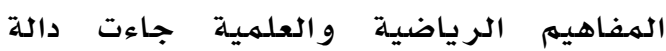

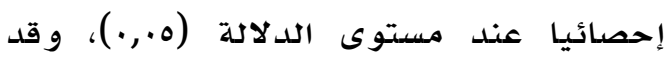

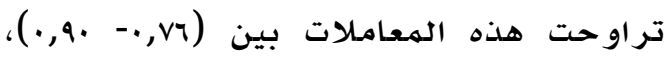
وهذا يدل على أن جميع مستويات الاختبـار تتمتع بالاتساق الداخلي. 


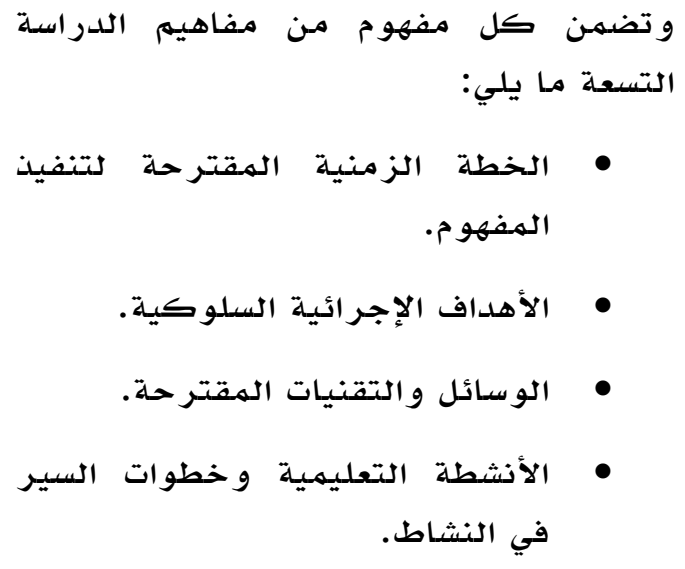

$$
\text { في النشاط. }
$$

وقد عرض الباحث الدليل على مجموعة من

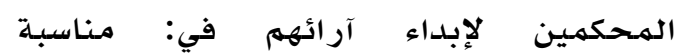

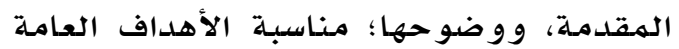

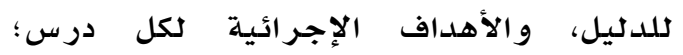
و مناسبة مر احل النموذج وخطوات تنفيذها؛ و مناسبة الأنشطة التعلمية.

تلدريس أطفال المجموعة التجريبية باستخدام الدراما التعليمية الدية

التقى الباحث بمعلمهة المجموعة التجريبية،

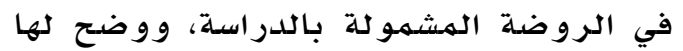

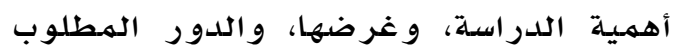

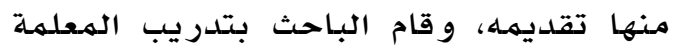
على التدريس باستخدام الدراما التعليميلة، حيث عقدت أربع جلسات متتالية لتعريف

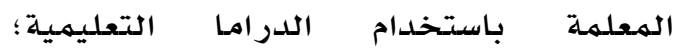

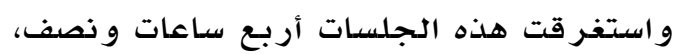
وزعت على ثلاثة أيام. ثم قام الباحث بتنفيذ

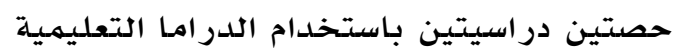

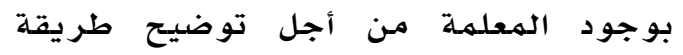

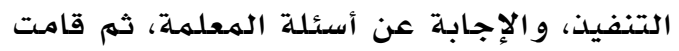

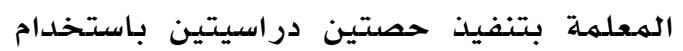

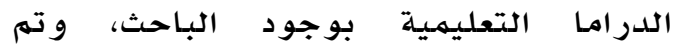
التباحث في طريقة تنفيذ المعلمة للحصدة،

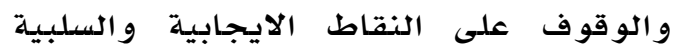
فيها، بهدف تحسين الأداء، وحضر الباحث البه

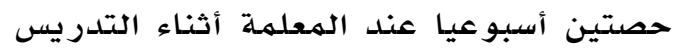

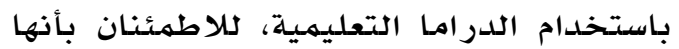

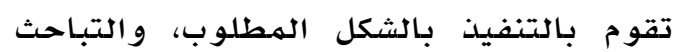
و مناقشة ما يستجد من أمور.
الأهداف العامـة لرياض الأطفال، وهي عبارة عن الأهداف الرئيسية التي تسعى كل رئل رياض الأطفال لتحقيقها ضهمن مناهجها، وتحديد

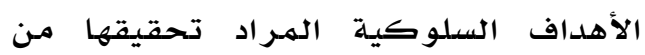

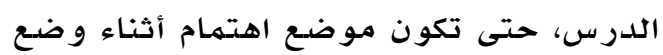
النص الدرامي، واختيار العقدة المنـاسبة التي

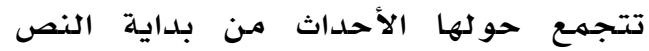
الدرامي، والتي تأخذ في الحل عند نهايـة النص الدرامي، وتحديد نقطة بداية النص الدس الدرامي، ووضوح النهاية التي ستصل إليها الأحداث في ذهن الباحث، قبل البداء في

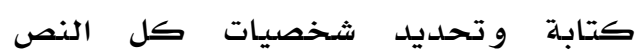
الدرامي، والتي سوف تدير الجمل الحوارية،

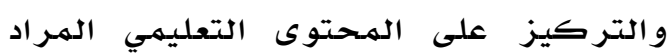

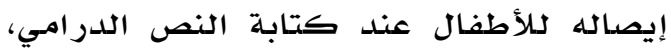
و إدخال عنصر التشويق والجذب في النص إدله

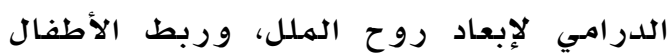
المشاهدين و الممثثلين بالأحداث و المـحتوى لهو التعليمي، اللذي يقدم من خلامل بلهن النص الدرامي، وتحديد النهاية المنطقية للنص النص

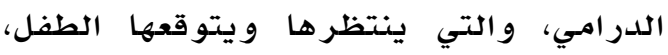

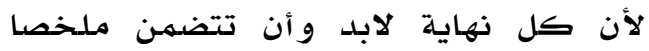

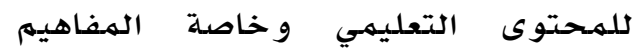
الر ياضية و العلمية.

\section{الهدف الرئيسي لدليل المعلمة}

كان الهدف من الدليل هو تسهيل مهممة

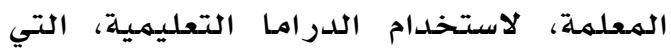
هي: أسلوب يستخدم سلسلة من النشاطات التي يقوم بها الأطفال، بتوجيه من المعلمهـة، لتحقيق نتاجات تعليمية محددة، كانت في

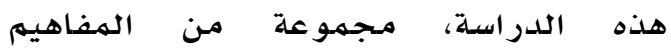

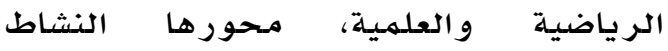
التمثيلي، المعتمدد على نص دريله درامي تمثيلي،

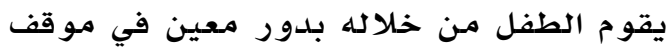

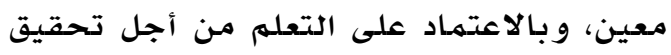

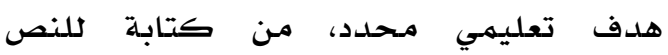

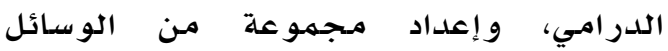

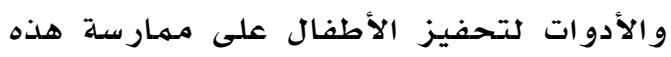

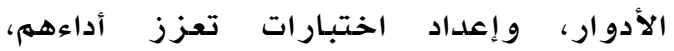
و تقيس مدى الكتساب الأطفال لـمفهوم. 


\section{نتائج الدراسة ومناقشتها}

قبل البدء بتطبيق الدراسة تم التحقق من

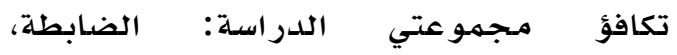

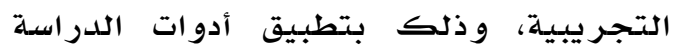

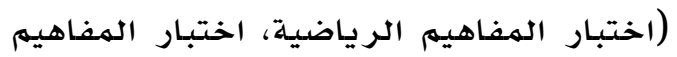

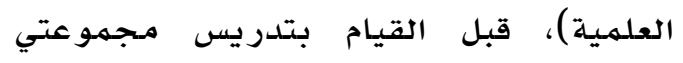

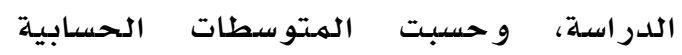

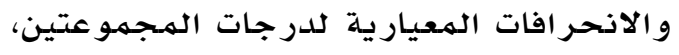

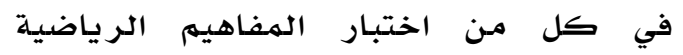

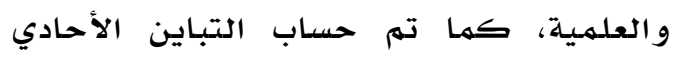

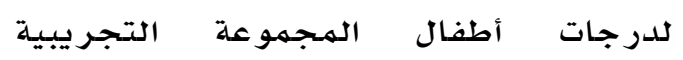

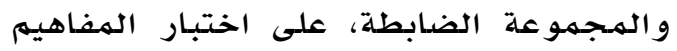

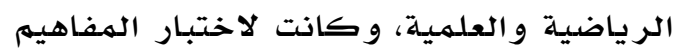

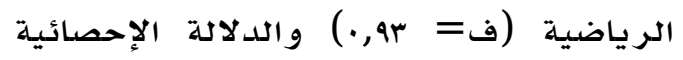

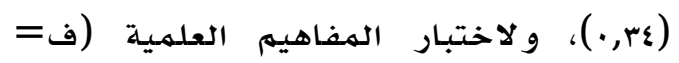

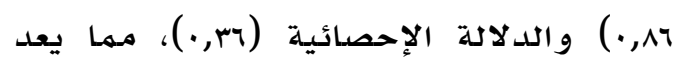

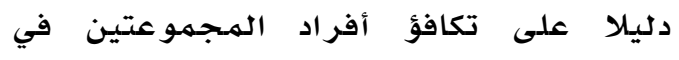
مستوى الأداء قبل البدء بتطبيق الدراسة.

نتائج السؤال الاول من أسئلة الدراسة: ما

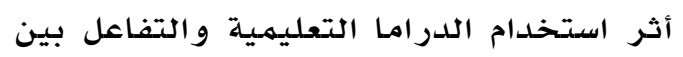

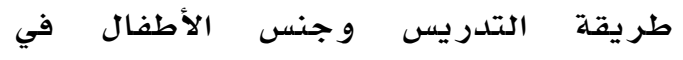
اكتساب المفاهيم الرياضية لدى الدى أطفال

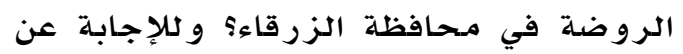
هذا السؤال تم حساب المتوسطات الحسابية

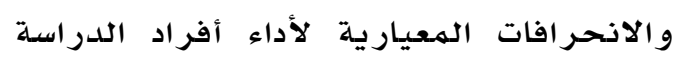

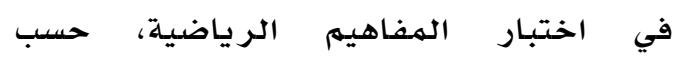

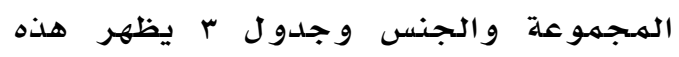

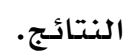

يبيّن جسـدول r و وجـود فـروق ظاهريسـة فـي

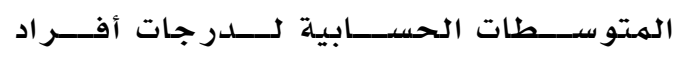

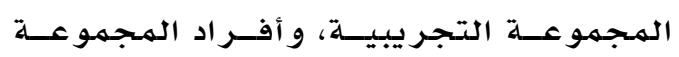

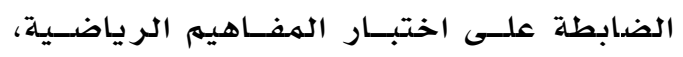

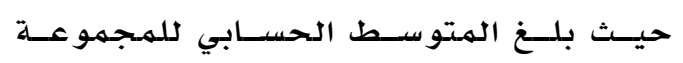

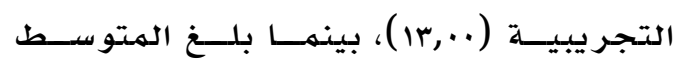

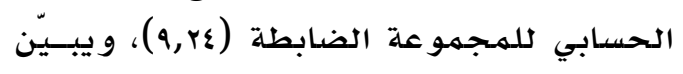

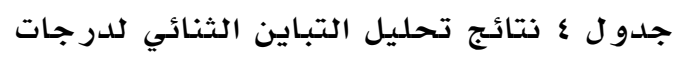

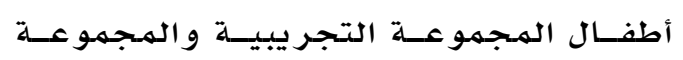
الضابطة في اختبار المفاهيم الرياضية.
وقد تم إتباع الخطوات الأتية في تدريس

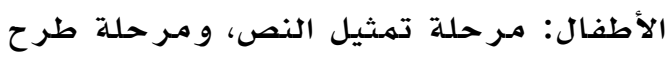

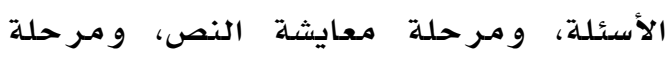

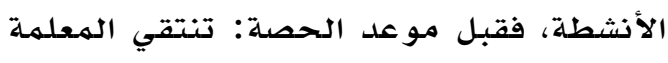

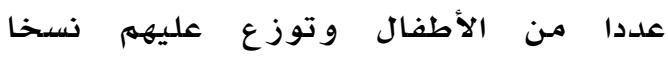
مصورة من النص الدرامي، وتوزع الأع الأدوار

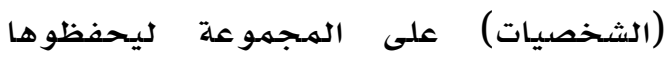

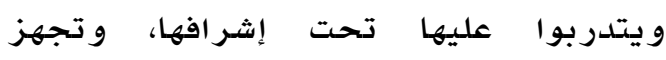

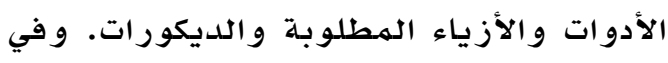

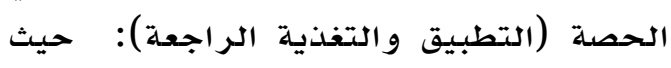

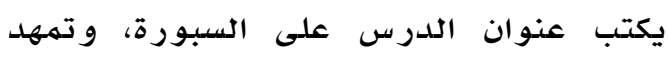

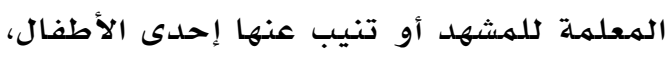

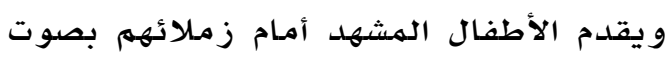

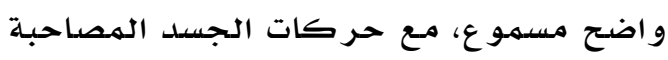

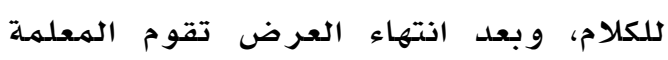

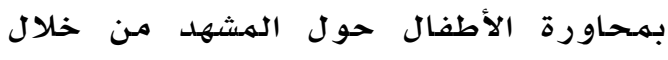

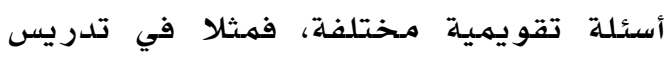

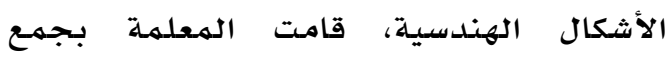
الأطفال على شكل حلقة، والخبر الهنهم بأنهم

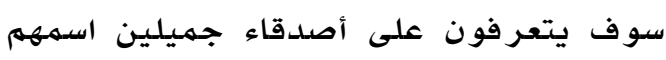

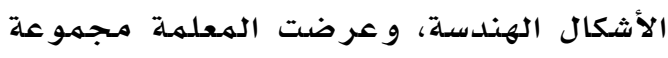

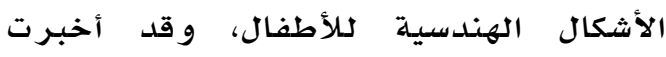

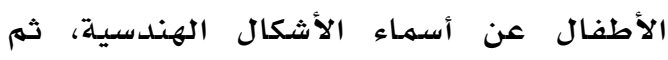

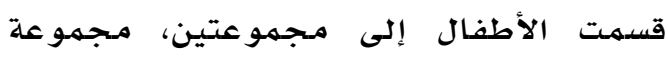

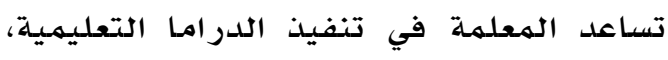

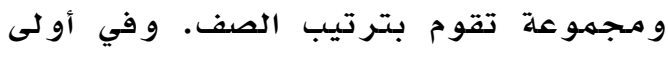

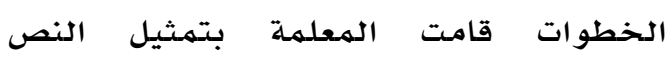

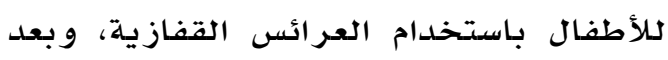

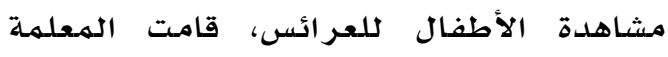

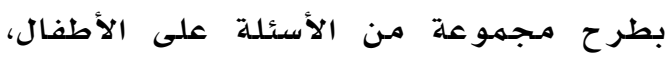

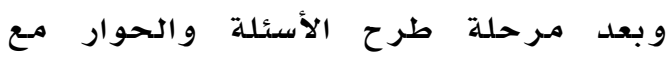
الأطفال حول مفهوم الأشكال الهندسية، قام

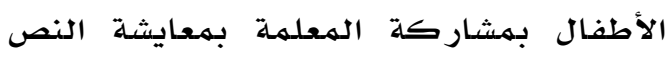

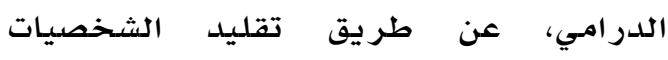

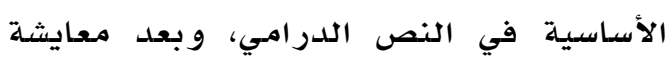

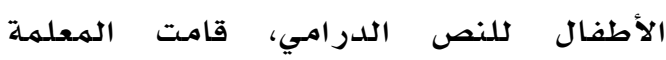
بتطبيق الأنشطة المرتبطة بمفهوم الأشكال

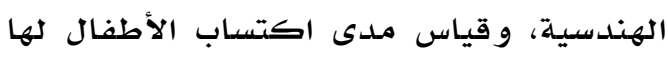

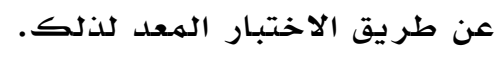


استخدام الدرراما التعليمية يثير انتباه

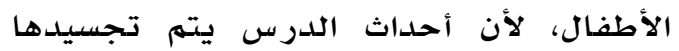

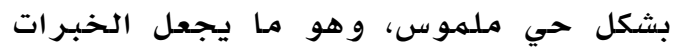
التي تقدم، لها تأثير مباشر على وهلى الأطفال،

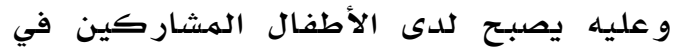

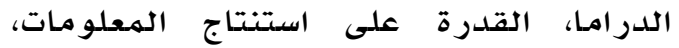

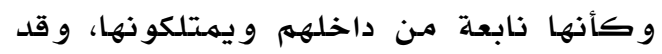

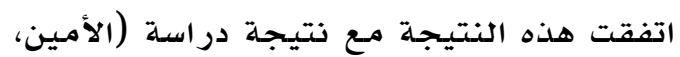

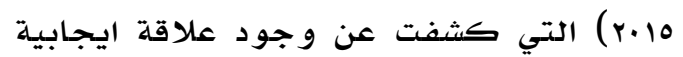
بين استخدام الأنشطة الدرامية في رياض الأطفال و التكيف الاجتماعي. ويمكن تفسير هذه النتيجة إلى التغيير في الصورة النمطية في التدريس الذي رافق الدراما التعليميلة، مـما جذب الذب الأطفال إليه الهيه وزاد تفاعلهم معه، وساهم بالتخلص من مشاعر التوتر و والخجل و وسلطة المعلمهة، حيث أن الدرامـا تتطلب استخدلام الأطفال لحو اسهم بشكل كبير ، كالإصغاء و التر كيز

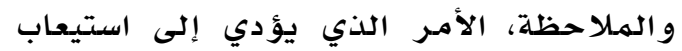

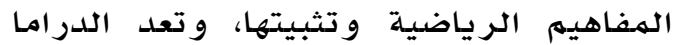
التعليمية تطبيقا لنظرية برونر في النيه النمو المعر في و التعلمى بالاكتشاف، حيث يرى أنه يمكن تعليم أي موضوع لأي طفل، ويتوقف

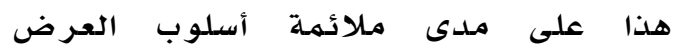

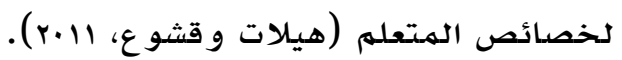
و يهكن أن يعزى تفوق أطفال الهجموعة

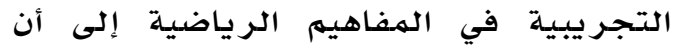

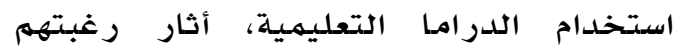

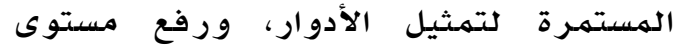

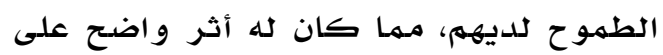

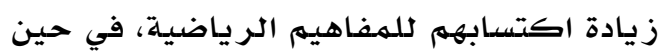
أن أطفال الهمجموعة الضابطة، لهم تتم إثارة قدراتهم ضهمن طريقة التدريس الاعتيادية،

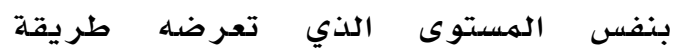
استخدام الدراما التعليمية، كها أن مرونة النهية

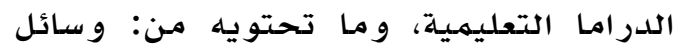

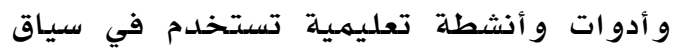
مـتع ومشوق، يسرت عملية تحقيق الاهداف

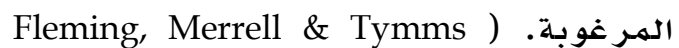

(2004
جدول ب

المتوسطات الحسابية والانحرافات المعيارية لأداء عينة الدراسة في اختبار

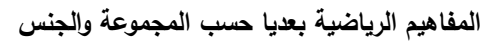

\begin{tabular}{|c|c|c|c|c|c|}
\hline الانعراف & الحسابي & العدد & الجنس & المجموعة & الاختبار \\
\hline I,YY & $1 r, .9$ & Ir & ذكر & التجريبية & المفــــــــيم \\
\hline $1, \leqslant 9$ & IY,QY & ir & أنثى & & الرياضية \\
\hline 1, זo & $1 r, .$. & ro & المجموع & & \\
\hline 1,01 & $9, \leqslant 0$ & 11 & ذكر & الضابطة & \\
\hline$r, . q$ & $9, \cdot v$ & $1 \varepsilon$ & أنثى & & \\
\hline I, I & $9, Y \leq$ & ro & المجموع & & \\
\hline
\end{tabular}

$$
\text { جدول ؛ }
$$

تحليل التباين الثنائي لارجات أطفال المجموعة التجريبية والضابطة في

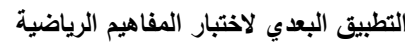

\begin{tabular}{|c|c|c|c|c|c|}
\hline الدلالة & قيمة & متوسط & درجة & مجموع & التباين \\
\hline الإحصائية & ف & المربعات & الحرية & المربعات & \\
\hline$\cdot, \cdots$ & $T \leqslant, \varepsilon$ & IVY,90 & 1 & IVY,90 & المجموعة \\
\hline غ د & $\cdot, \Gamma \varepsilon$ & $\cdot, 9 Y$ & 1 & •, 9r & لجنس \\
\hline \multirow[t]{2}{*}{ غ } & $\cdot, \cdot 7$ & .10 & 1 & $\cdot, 10$ & لمجموعة X \\
\hline & & $r, 79$ & $\leqslant 7$ & 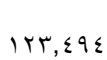 & الخطأ \\
\hline
\end{tabular}

يبين جدول ع وجود فرق ذو دلالة إحصائية بين المتوسط الحسـابي لدرجات الأطفال في

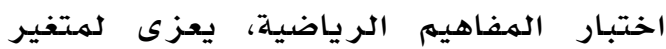
طريقة التدريس، حيث كانت قيمة (فيمان

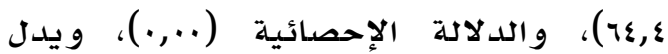
ذلك على وجود فارق لصالح الهـهموعة

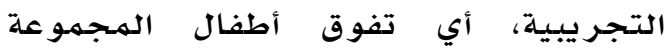

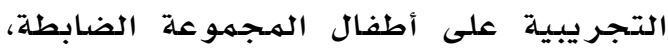
كما يبين جدول ع عدم وجود أثر للتفاعل بين طريقة التدريس، وجنس الأطفال في اختبار الهفاهيهم الرياضية، حيث كانت قيمة

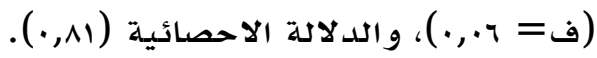
ويمكن تفسير النتيجة إلى أن استخدام الدراما التعليمية جهـع بين التعليه و اللعب، و تنشيط الطفل عقليا ووجدانيا وحركيا، لبناء تعلمها معتمدا على ذاته، عن طريق

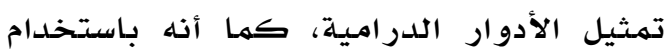

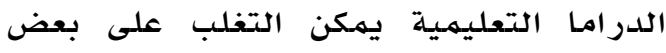

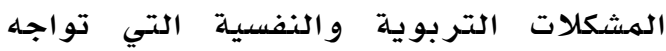
الأطفال، وخاصدة تلك المشكلات التي تتعلق بضعف قدرتهم على التركيز، حيث أن 
الروضة الذين يدرسون باستخدام الدراما

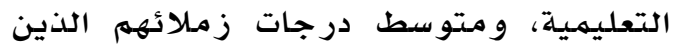

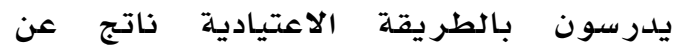
التفاعل بين طريقة التدريس، وجنس التسول الأطفال في اكتسـاب المفاهيم الرياضية

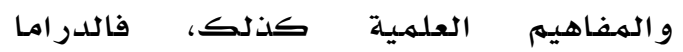
التعليمية قامت على تحسين مستوى تحصيل

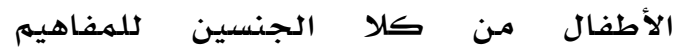
الرياضية والعلمية؛ وذلك لأنها تعمل على ملى لهن إيجاد مناخ مـريح في غرفة الصف، ووفي هذه

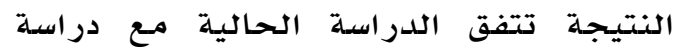

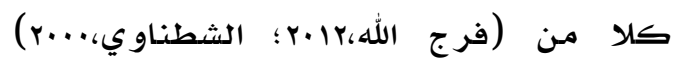
حيث كشفت كل منهما عن عدم وجود أثر

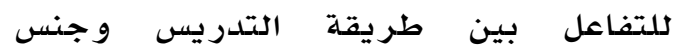
الأطفال في اكتساب المفاهيم الرياضية. و يمكن أن تعزى هذه النتيجة إلى تفاعل

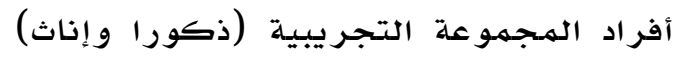

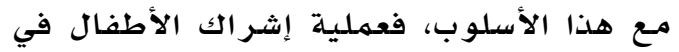

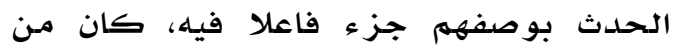

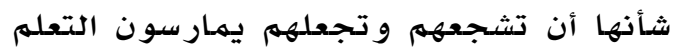

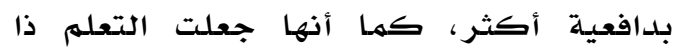

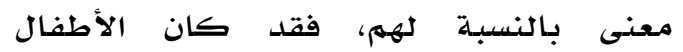
يمارسون عملية التمثيل بما تنطوي عليه من من

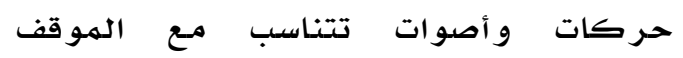
بحماس كبير •

و قد يعزى ذلك إلى تكافؤ الفرص التعليمية

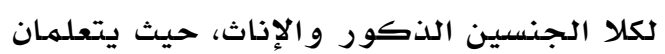

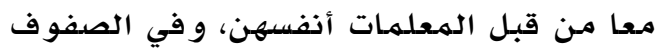
الدراسيـة نفسها، حيث أن التعليهم في رياض

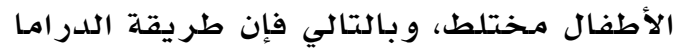
التعليمية تلائم كلا الجنسين، وتؤدي إلى مادئ زيادة متعـة التعلهم، وإثارة الحماس عندهمه. و تتفق هذه النتيججة مـع نتائج دراسة الحربـات

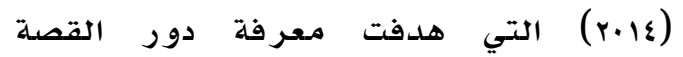
الدرامية في إكساب أطفال رياض الأطفال

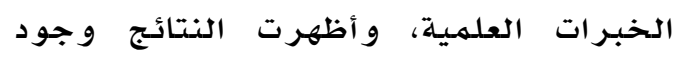
فروق ذات دلالة إحصائية بين متوسطات درجات الأطفال بين المـجموعة التجرويبية

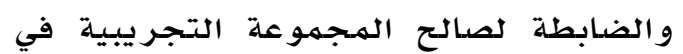

ويهكن تفسير النتيجة إلى أن استخدام

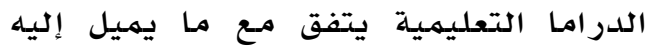

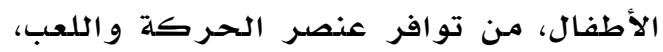
الذي ساعد على إثارة اهتمام الأطفال، فيتابع

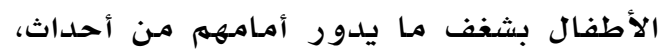
فيصبح الطفل مشاركا إيجابيا في التعله، بدلا من كونه متلقيا سلبيا، و هذا كله ييسر الفهم و يعمقه، مها يؤثر على تعلهم الحقائق و المفاهيم الر ياضية و استدعائها عند الحهاجة.

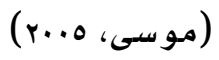

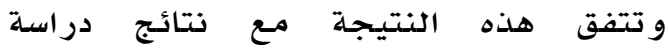

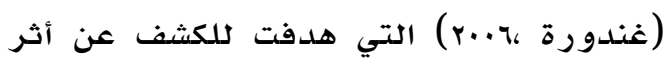

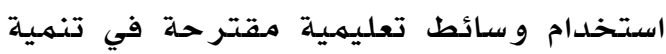
الهفاهيم الرياضية، و الكثف عما إذا كان

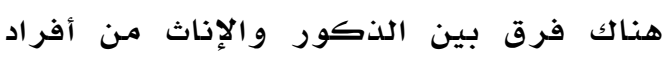
المجمووعة التجريبية في تحصيل المفاهيم

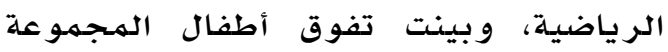

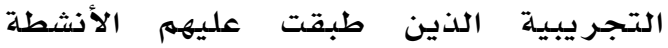
باستخدام الوسائط التعليمية المقتر حلة. وتتفق هذه النتيجة مـع نتائج دراسلة عبد

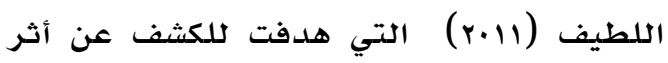
بر نامـج أنشطة فنية مقترح لتنهية واكتسباب بعض الهفاهيم العلمية و الرياضية لدي طفل

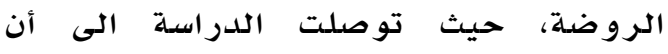

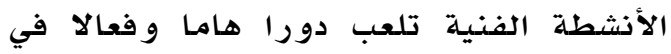
إكساب المفاهيم العلمية والرياضيـة لطفل الروضدة، لأنها تتيح للطفل فرصدة استخدام حواسـه و الاعتماد على ذاته في استكشاف مـاف حو له، والإجابة عن الأسئلة التي تحيره، كها

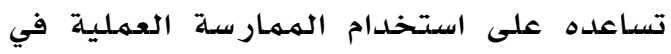
إكساب المفهوم، فالفن هو المكمل للعلوم مها يتيح أمام الطفل فرص عديدة إلدة تساعده

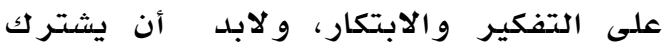
الأطفال في اختيار الأعمال والأنشطة التي ولئي

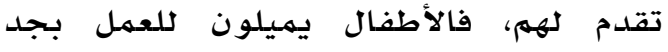
و نشاط إذا اشترك كوا بأنفسهم في اختيار تلك الأنشطة. كما بينت النتائج أنه لا يوجد فرق ذو دلالده إحصائية بين متوسطي ل درجات أطفال 
يبين جلدول ه وجود فرق ذو دلالة إحصائية بين الهتوسط الحسابي لدرجات الأطفال في

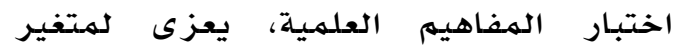

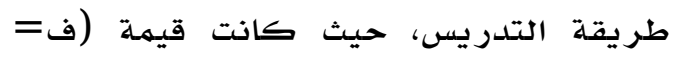

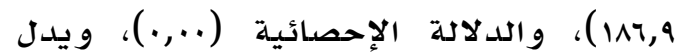

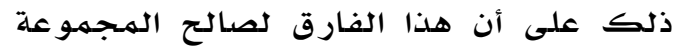

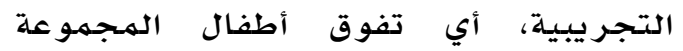

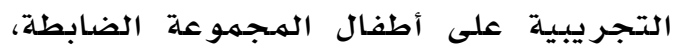

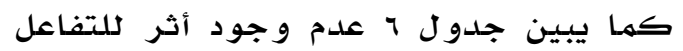
بين طريقة التدريس وجنس الأطفال في اختبار المفاهيم العلمية، حيث كانت قيمة

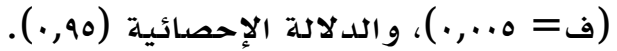
ويمكن تفسير هذه النتيجة إلى اعتهماد الدر اما التعليميلة على نشاط الطفل، و اعتبـاره

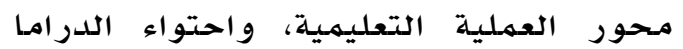

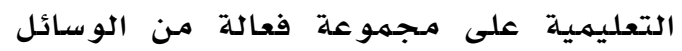

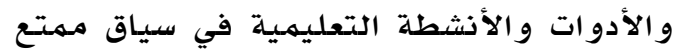

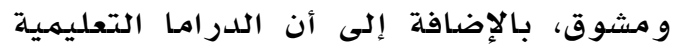
تضفي جوا من المرح مندو عند الأطفال، مهما يجعل التعلهم لديهم أبقى أثرا، ويسهم في التهري

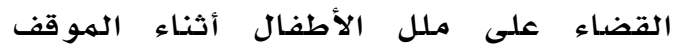

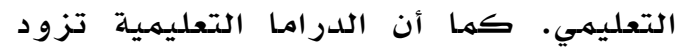

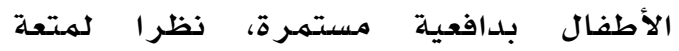

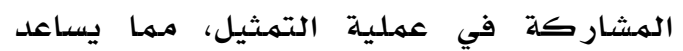

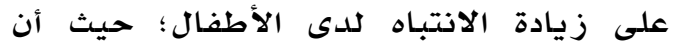

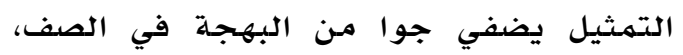

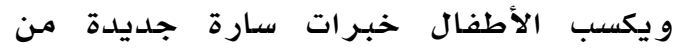
خلال الهشاركة في النشاط التمثيلي. (Crowshoe \& Bkford, 2005) هذه النتيجة الى أن الدراما التعليمية تحول ولهئ آن تعزى

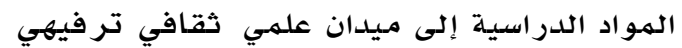

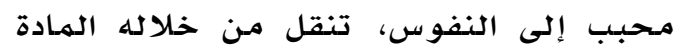

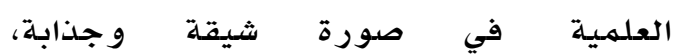

الاختبار التحصيلي المصور البعدي. وتتفق

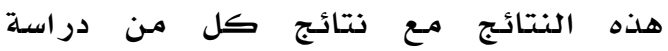
Conrad, 2002 Soydan \& Quadir, 2013)

(Young, 2000

نتائج السؤال الثاني من أسئلة الدراسة: مـا أثر استخدام الدراما التعليمية والتفاعل بين

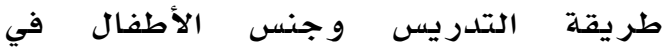

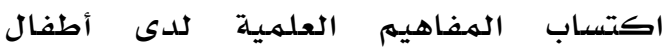

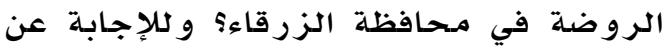

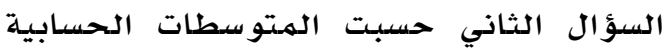

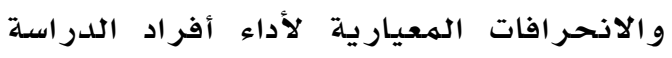

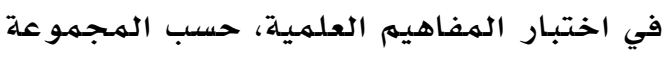

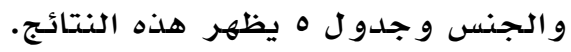
جدول

المتوسطات الحسابية والانحرافات المعيارية لأداء عينة الدراسة

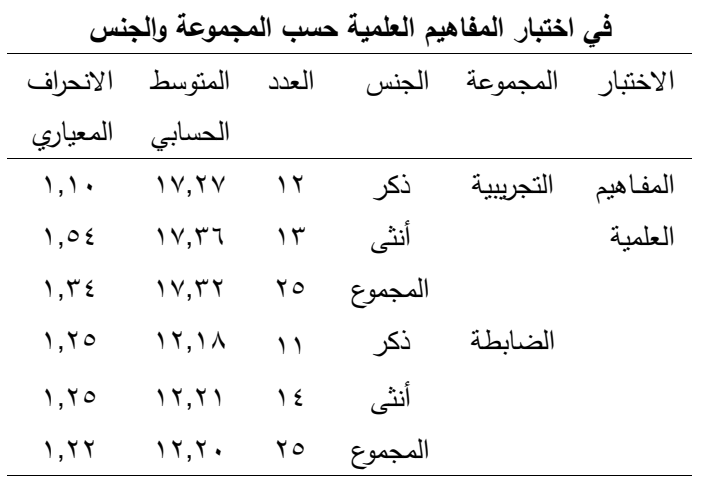

يبيّن جــدول ه وجـود فـروق ظاهريسـة فسي

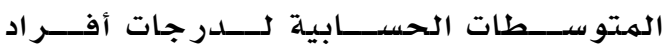

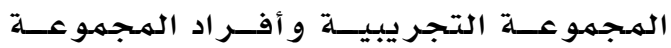

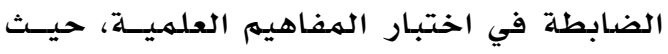

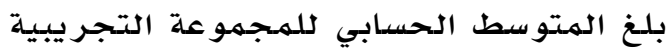

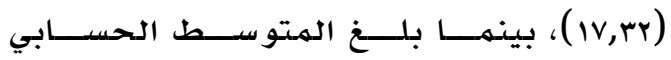

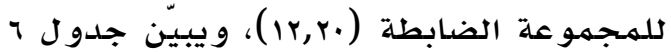
نتائج تحليل التباين الثنائي لدرجات أطفـال

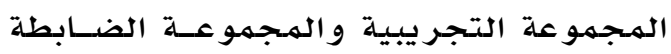
في اختبار الهفاهيم العلمية.

جدول 1

تحليل التباين الثنائي لارجات أطفال المجموعة التجريبية والضابطة في التطبيق البعدي لاختبار المفاهيم العلمية

\begin{tabular}{|c|c|c|c|c|c|}
\hline الدلالة الإحصائية & قيمة ف & متوسط المربعات & درجة الحرية & مجموع المربعات & التباين \\
\hline$\cdot, \cdots$ & 117,9 & Mrr,OTA & 1 & MYY,OTA & المجموعة \\
\hline غ غد & $\cdot, \cdot Y \leq$ & $\cdot, \cdot \leq r$ & 1 & $\cdot, \cdot \leq r$ & الجنس \\
\hline \multirow[t]{2}{*}{ غ } & $\cdot, \ldots$ & $\cdot, \cdots \wedge$ & 1 & $\cdot, \cdots \wedge$ & المجموعة × الجنس \\
\hline & & I, YYY & $\leq 7$ & $\vee q, r q$. & الخطأ \\
\hline
\end{tabular}


الحوار والهناقشة، و والاكتشاف الهوجه،

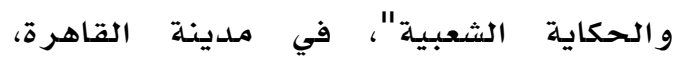

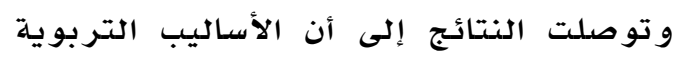
لها دور فعال في اكتسـاب طفل الروضدة

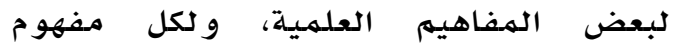
الأسلوب المناسب لتوصيله.

كما بينت النتائج أنه لا يوجد فرق ذو دلالة إحصائية بين متوسطي ل درجات أطفال

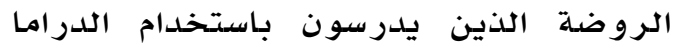

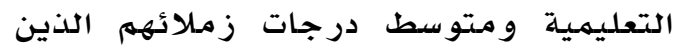
يدرسون بالطريقة الاعتيادية ناتج عن الاعن التفاعل بين طريقة التدريس وجنس الأطفال

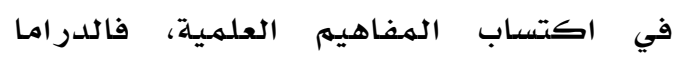
التعليميية قامت على تحسين مستوى تحصيل

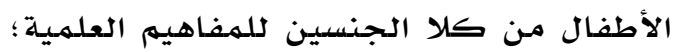

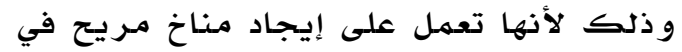
غرفة الصف، وركذلك تعمل على تحقيق مبدأ تكافؤ الفرص ص التعليميلة، و لهذا فإنها تعد وله من الاستراتيجيات المفضل استخدامها في رياض الأطفال.

وقد اتفقت نتيجة هذه الدراسة مـع نتائج

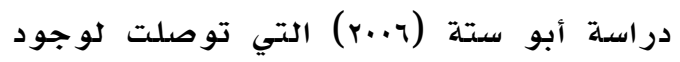
فروق ذات دلالة إحصائية في المريه لمفاهيم

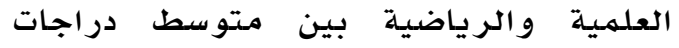

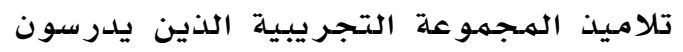

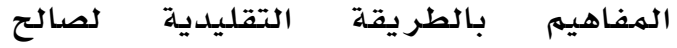

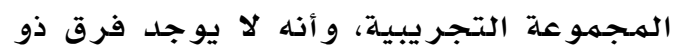
دلالة إحصائية بين متوسطي درجات أطفال

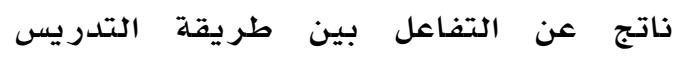
وجنس الأطفال، وقد اتفقت نتيجة هذه

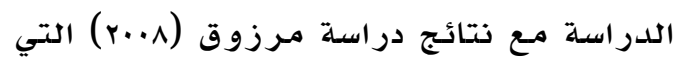

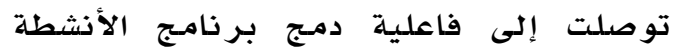
وبر امـج الروضـة بصفة عامـة معا، للتأكيد على المفاهيم العلمية واثارة الدافعية نحو الهو التعلهم الذاتي للطفل.

التوصيات

من خلال النتائج السابقة تم التوصل إلى عدد من التوصيات و التي مـن أهمها:
مها ييسر عملية الفهم، وذلك لأن الدراما التعليمية لها آثار إيجابية عديدة على على على الأطفال، ففي الوقت الذي يشاهد فيه الطفل

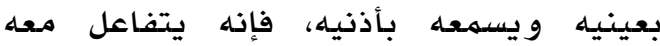
بحواسـه ووجدانه، مهما يجعل الهـادة الهقدمـة

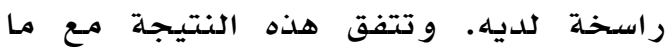

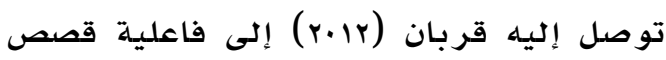
الرسوم المتحركة في تنمية بعض المضه المفاهيم العلمية والقيهم الاجتماعية. و يمكن أن تعزى هذه النتيجهة إلى أن الدراما

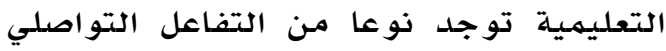

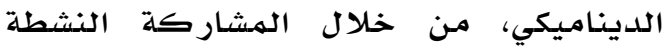

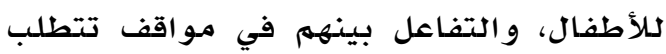
إعمال العقل، وتستثمر حركتهم، وبناء المعارف بـأنفسهم، وهذا مـن شأنه تحقيق التعلهم ذي المعنى، وهو ما يتفق مـع مبادئ التعلهم النشط وروح البنائية، في حين أنه

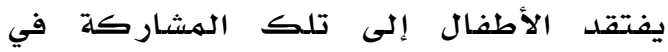
البيئة الصفية الاعتيادية، حيث تسيطر عليها

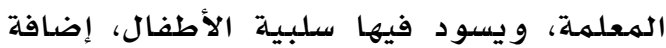
الى أنها لا ت تراعي الفروق الفردية بين الأطفال، ولا تناسب طبيعتهم. ( Creech \& (Bhavnaari, 2002 و هذا ما ذهب إليه عبيد (Y...r) الذي يرى أن الدور التربوي للمعلمهة عند استخدام الدرامـا التعليمية، بأن تكون منسقة لبيئة التعلهم و المشجعة للاستقلال الفكري ليفتح المـجال

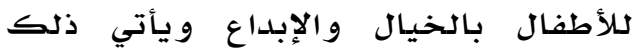
مواكبا للتقدم السريع وتحديدات هذا العصر .

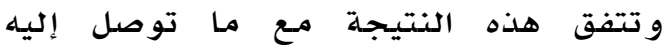

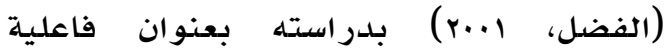
الأركان التعليمية في تنمية المفاهيم

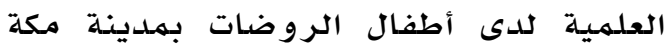

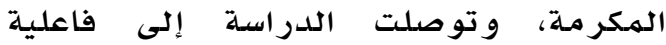
الأركان التعليمية، وخاصة ركنة ركن الاكتشاف

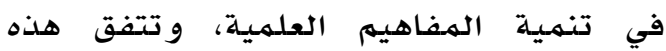

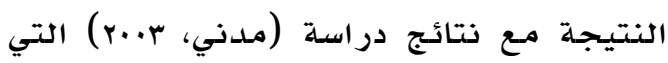
كشفت عن فاعلية استخدام بعض أساليب التربية في اكتساب طفل الروضدة المفاهيم

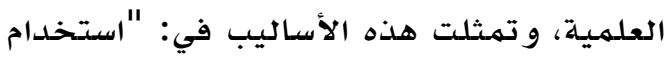




$$
\text { دار الثقافة للنشر والتوزيع. }
$$

الأمين، سعد (10.r). الأنشطة الدرامية في

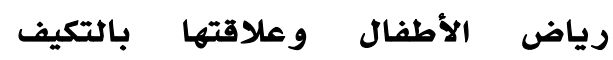

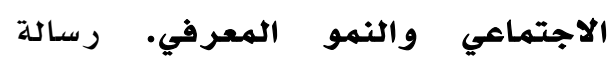

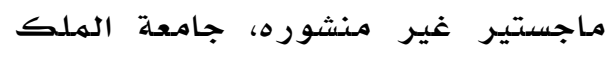

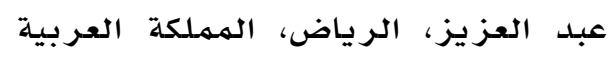

$$
\text { السعو ديلة. }
$$

بدوي، رمضان (r/r). ت تنمية المفاهيم

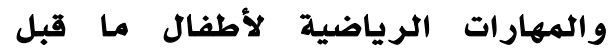

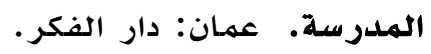

بدوي، محمود (11) (11). نمو المفاهيم العلمية

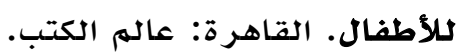

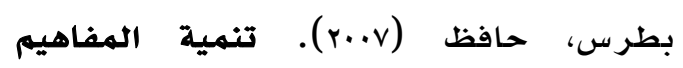

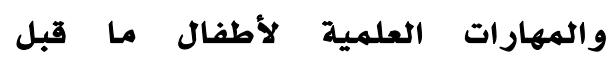
المدرسة. عمان: دار المسيرة.

الجدبة، صفية أحمد (r.|r) فاعلية توظيف استراتيجية التخيل الموجه في تنمية التهل

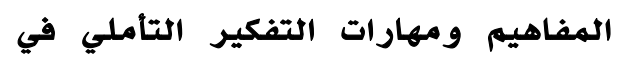

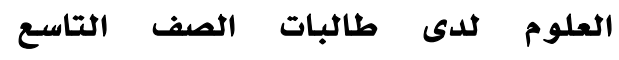
الأساسي، رسالة ماجستير غير منشورة،

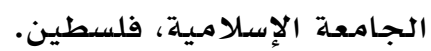
الحربات، ريما ( (عا•r). دور القصدة في

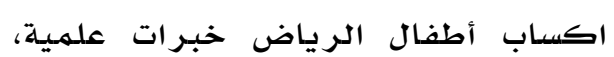
دراسـة ميدانية في مدينة دمشق. مـلة اهلة اتحاد الجامعات العربية للتربية ورية ولمئه

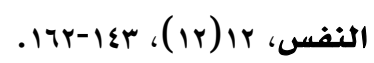

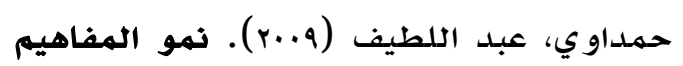
العلمية والرياضية عند الأطفال. دبيل دار التقله.

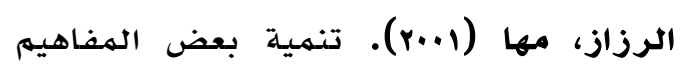

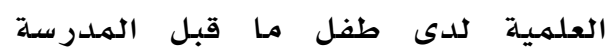
باستخدام الوسائط التعليمية المتعددة، رسالة ماجستير غير منشورة، كلية التربية، جامعة طنطا، مصر مياهير

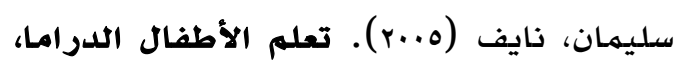
المسرح، الفنون التشكيلية، الموسيقى. عمان: دار الحامد للنشر والتوزيع.
1. ضرورة تضمين مناهج رياض الأطفال

نصو ص درامية ومسرحية تتناسب مـع هذه المـر حلة. r. توصية إلى وزارة التعليه، بعقد دورات لتدريب معلمات رياض الأطفال على تحويل المـادة التعليمية إلى دورلى نصو ص در اميلة و مسرحية و استخدلامها لهمادها في الغر فة الصفية. r. استخدام معلمـات رياض الأطفال لطريقة الدراما التعليمية في تعليهم الأطفال إلى جانب طرق التعلى التعليه

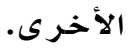

ع. استخدام وسائل تعليميلة مفيدة لهذه الاستراتيجية حتى تكون المـادة أكثر

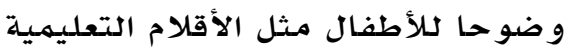
و العينات المهجسمة. ه. تضمين برامج إعداد المعلم خبرات تمكنهم من استخدام الدرامـا التعليهي التهيم في تخطيط التدريس، وتهن المنفيذه، و تقو يمهـ. المقتر حات

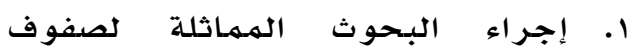

دراسيلة أخرى في التعليم الابتدائي

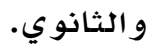

Y. دراسـة مقارنة لاستخدام الدرامـا

التعليمية و القصص و لعب الأدوار في لنهارل

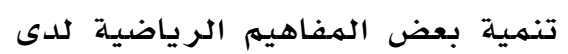
أطفال رياض الأطفال.

$$
\text { المراجع }
$$

\section{References}

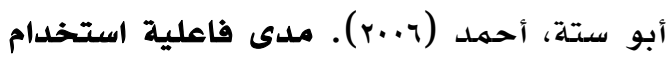

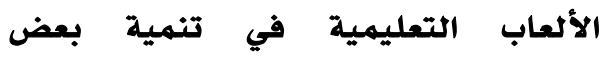
المهارات الرياضية للى مرحلة رياض

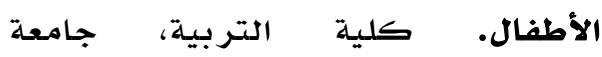
المنصورةة، مصر .

أبو عاذرة، سناء (r.r). تنمية المفاهيم العلمية و مهارات عمليات العلم. عمان: 
الهفاهيم العلمية والقيم الاجتماعية

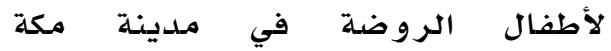
المكرمة. رسالة دكتورواه غير منشورة، كلية التربية، جامعة أم القرى، المملكة العربية السعودية.

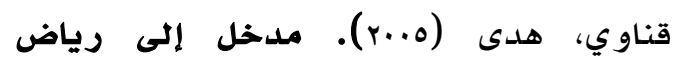
الأطفال. الرياض: مكتبـة الرشد للنشر .

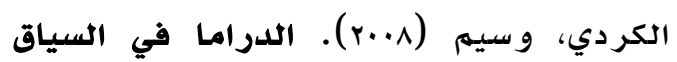

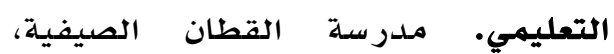
جرش، الاردن.

اللوح، عصام (عا+r). مفهوم الدراما و أثرها

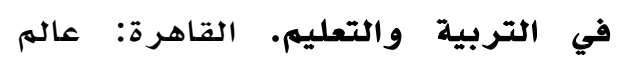
الكتب.

مدني، مرفت (r.r). فاعلية استخدام بعض

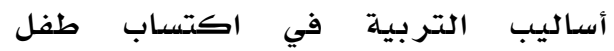

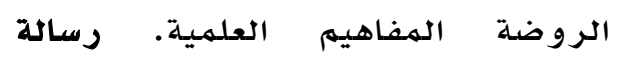
ماجستير غير منشورة، كلية رياض الأطفال، جامعة القاهرة، مصر.

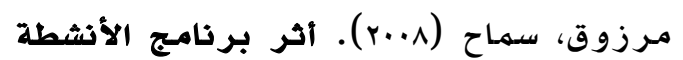
المقترح على تنمية المفاهيم العلمية. رسالة ماجستير غير منشورة، كلية

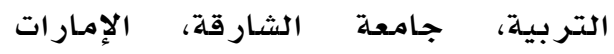
العربية المتحدة.

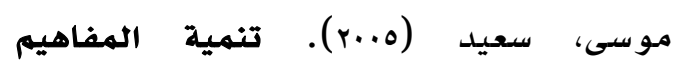
الحياتية لطفل الروضة من خلال أنشطة

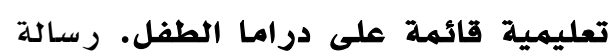
دكتور اه، جامعة حلوان، القاهرة، مصر . نصار، محمد و وصوالحة، معتصهم (....). الدراما التعليمية نظرية وتطبيق. إربد، واجها، الأردن: المركز القومي للنشر . هيلات، مصطفى وقشوع، ميادة (11) (r). الرسم والموسيقى والدراما في تربية الطفل. عمان: وزارة الثقافة.
الشطناوي، إياد (......). أثر استخدام طريقة مسرح الدمى على التحصيل في وحلدة القسمة في مادة الرياضيات وأثره على ملى التفكير الإبداعي والخيال عند طلبة ولهية الصف الثالث الأساسي. رسالة ماجستير غير منشورة، جامعة مؤته، الأردن. الصراوي، إلهام (^••r). الدراما التعليمية.

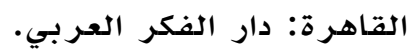

عبد اللطيف، ايمان (11) (r). برنامج أنشطة

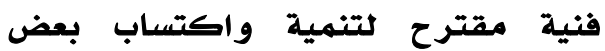
المفاهيم العلمية والرياضية لدى طفل الروضة. رسالة دكتوراه غير منشورة،

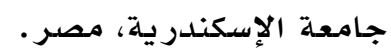

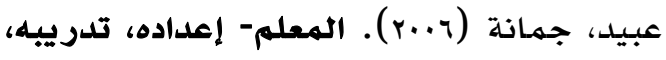

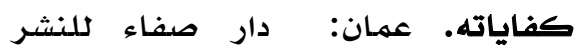
و التوزيع.

عزة، خليل (r..v). تنمية المفاهيم العلمية

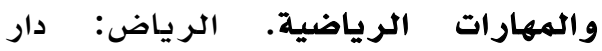
الشر بتين.

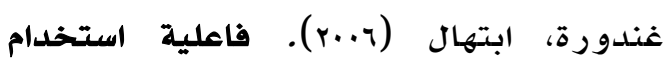
و سائط تعليمية مقترحة في تنمية بعض التول المفاهيم الرياضية لدى أطفال الروضة فيهيه

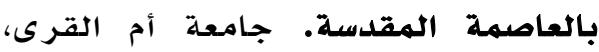
مكة الهكر ملة. فرج الله، عبد الكريم (r/r). أثر استخدام

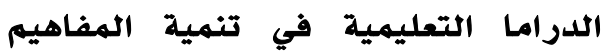
الرياضية للى تلامذة الصف الأول الأساسي بقطاع فزة. رسالة ماجستير غير منشورة، جامعة عزه، فلسطين.

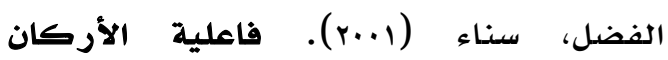
التعليمية في تنمية المفاهيم العلمية للى أطفال الروضات من واقع اختبار تحصيلي لكلاطفال بمكة المكرمة. رسالة ماجستير غير منشورة، جامعة أم القرى،

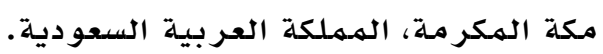
قربان، بثينة (r./r). فاعلية استخدام

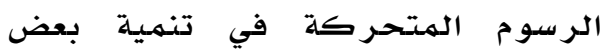


Bedore, B. (2004). 101 Improve games for children and adults. Alameda, United States: Group West, Hunter House Inc.,

Clements, S. (2006). Building math through every day. Journal Articles, Opinion Papers Reports, 19, 50-57.

Cokadar, H. \& Yılmaz, G. (2001). Teaching ecosystems and matter cycles with creative drama activities. Journal of Science Education and Technology, 19(1):80-89.

Conrad, D. (2002). Drama, media advertising, and inner-city youth. Youth Theatre Journal, 16, 71-87.

Creech, N. \& Bhavnaari, N. (2002). Teaching elements of story through drama to 1 grader: child development frameworks, Childhood Education, 74 (4): 219 - 225.

Crowshoe, L. \& Bkford, J. (2005). Interactive drama. Unpublished master thesis, university Ohio. U.S.A.

Fernsler, H. (2005). A compassion between the test scores of third grad children who receive drama in place of traditional social studies instruction and third grade children who receive traditional social studies instruction. European Journal of Teacher Education. 1, 3-47.

Fleming, M., Merrell, C. \& Tymms P. (2004). The impact of drama on pupils' language, mathematics, and attitude in two primary schools. Research Drama Education, 9(2), 177-197.

Hui, A. \& Lau, S. (2011). Drama education: a touch of the creative mind and communicative-expressive ability of elementary school children in Hong Kong. Thinking Skill and Creativity, 1(1), 34-40.

Juliet, S. (2008). Drama for at-risk students: A strategy for improving academic and social skills among public middle school students. ERIC, ED502068.

Lashelle, D. (2003). Ideas for using drama through instruction, (ERIC) Document Reproduction Service, No. ED441007.

Mages, W. (2013). Does creative drama promote language development in early childhood? A review of the methods and measures employed in the empirical literature. Review of Educational Research. 78(1), 124-137.

Soydan, S. \& Quadir, S. (2013). Observation of the effectiveness of drama method in helping to acquire the addition- subtraction skills by children at preschool phase. Educational Research and Reviews, 8(18), 1689-1697.

Young, D. (2000). Reality drama: The drama classroom as a place for disclosure. NJ (Drama Australia), 24(1), 111-121. 